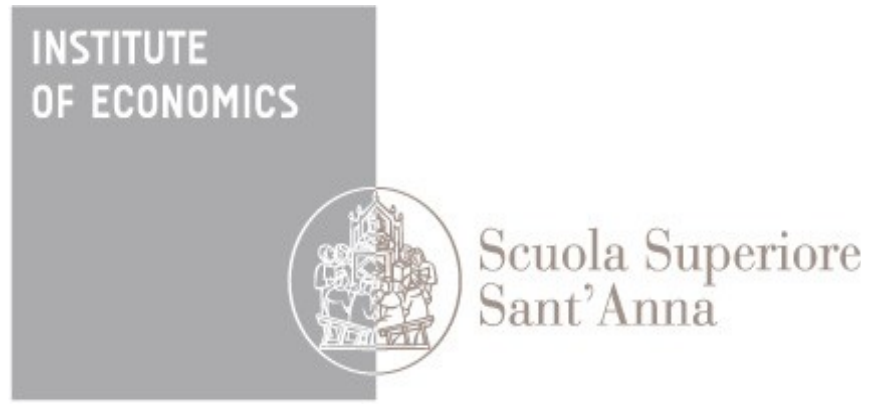

LEM | Laboratory of Economics and Management

Institute of Economics

Scuola Superiore Sant'Anna

Piazza Martiri della Libertà, 33 - 56127 Pisa, Italy ph. +3905088.33 .43$

institute.economics@sssup.it

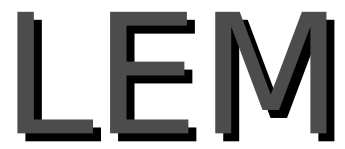

Working Paper Series

\title{
Digitalization, routineness and employment: An exploration on Italian task-based data
}

a National Institute for the Analysis of Public Policies, INAPP, Rome, Italy. ${ }^{b}$ University of Camerino, Italy.

c European Commission - Joint Research Center, Seville, Spain. 


\title{
Digitalization, routineness and employment: An exploration on Italian task-based data
}

\author{
Valeria Cirillo ${ }^{1}$, Rinaldo Evangelista ${ }^{*}$, Dario Guarascio ${ }^{1}$, Matteo Sostero ${ }^{3}$ \\ ${ }^{1}$ National Institute for the Analysis of Public Policies, IN APP, Rome \\ ${ }^{2}$ University of Camerino \\ ${ }_{3}^{3}$ European Commission - Joint Research Center, Seville
}

\begin{abstract}
This paper explores the relation between the digitalization and of labour processes, the level of routineness of tasks and changes in employment. The levels of digitalization and routineness of occupations in 796 5-digit ISCO professional groups are measured using data from a unique Italian profession-level survey on skill, task and work contents - the INAPP-ISTAT Survey on Italian Occupations (ICP), an $\mathrm{O} *$ NET-type dataset. We develop three novel digitalization indices: a digital use index measuring the use of digital devices and technologies in the workplace, a digital skills index assessing the familiarity and skill in using digital technologies, and a digital tasks index capturing the frequency and importance of selected digital tasks. Using the same data-source the Autor and Dorn routine task intensity index is also computed. This allows us to explore, based on robust indicators on routinization and digitalization, the existence and the strength of a "routinized biased technological change" specifically associated to the use of digital technologies. Results show the multifaceted nature of both digitalization and routineness processes, both characterized by strong sectoral specificities and by being strongly associated with the skill content of labour professions. Professions characterized by higher digital skills are those showing the best employment performances (although this holds only in manufacturing sector). Both the descriptive and econometric evidences show a negative employment dynamics among professions combining high level of digitalization and routineness.
\end{abstract}

* This project has received funding from the European Union Horizon 2020 Research and Innovation action under grant agreement No 822781

(C) 2019. This manuscript version is made available under the CC-BY-NC-ND 4.0 license 


\section{Introduction}

The digital revolution is widely expected to change economic and social paradigms, in the same way that previous technological revolutions have shaped long-term cycles of economic growth and structural change (Freeman and Louçã, 2001; Brynjolfsson and McAfee, 2014). There is however less agreement regarding the effects of digitalization on employment. A lively debate on the subject - largely dominated by impressionistic views - contrasts the spectre of mass technological unemployment with optimistic forecasts on the opportunities resulting from digitalization (Arntz et al. 2016; Frey and Osborne, 2017; OECD, 2018). However, there is still limited empirical evidence on the topic, because of the challenge in conceptualising effective measurements of a multifaceted phenomenon such as digitalization (McKinsey Global Institute, 2015; Calvino et al., 2018) and grasping its differentiated effects on employment in the different productive and social contexts (Guerrieri and Bentivegna, 2012; Evangelista et al., 2014). Until recently, the basic conceptual and methodological framework used to estimate the employment impact of digitalization has been rooted in a neoclassical-type production (labour demand) function and on a narrow view of digitalization. The implicit underlying assumption of such an approach is that digital technologies can be treated as any other capital input, measured through the acquisition and use of specific information and communication technology items, thereby dismissing the multifaceted nature of digital technologies, activities and competencies, able to reshape economies and societies.

This work quantifies the level of digitalisation of occupations and provides new evidence about the impact of digitalization on employment. We rely on a uniquely detailed professional dataset on tasks, skills, work attitudes, and working conditions regarding all Italian occupations: the INAPP-ISTAT Survey on Occupations (Indagine Campionaria sulle Professioni, ICP hereafter), an O*NET-type dataset developed by the Italian National Institute for Public Policy Analysis. Using the ICP survey we measure the extent of professional digitalization using occupational-level (i.e., based on ISCO taxonomy) information on digital-related jobs profiles, tasks and work contents. The numerous specific sections and questions contained in the ICP questionnaire dealing with digitalization have been examined and the answers used to measure (in each ISCO group) two key dimensions of digitalization: those related to specific digitalrelated activities performed, and those related to the actual use of digital devices and technologies.

Moreover, this work investigates the relationship between the digitalization of occupations and their routineness. As discussed in the next section, the existence of a strong nexus between digitalization and routineness is highlighted by a large amount of literature but much more rarely such a relationship has been explored empirically combining data on both phenomena. ${ }^{1}$ This work aims at filling this gap. Data drawn from the CPI survey are also used to build indicators measuring the level of routinization of the labour tasks. The combined impact of digitalization and routineness on employment will be assessed both at the level of professional groups (ISCO classes at four digit) and at industry (NACE 3 digit) level. This allows us to explore, using robust indicators on routineness and digitalization, the existence and the strength of a "routine-biased technological change" (Autor, 2013 and Autor and Dorn, 2013) specifically associated to use of digital technologies and competencies as well as do identify professional groups and industrial sectors where such phenomenon is particularly relevant.

\footnotetext{
${ }^{1}$ Most of the existing empirical contributions either look at the effects of the level of routinization on employment or at the employment impact of ICTs implying a necessary bi-univocal relationship between the two elements and processes.
} 
Compared to most of the existing analyses predicting a negative impact of digitalization on employment, we argue that a proper understanding and empirical assessment of such an impact requires considering how digitalization interacts with the technological and organizational context in which takes place. In fact, far from considering digitalization as an ad-hoc technology-fully-supply-side shock, we build on the evolutionary approach emphasizing the role played by different organizational features in explaining the level and scope for digitalization and its diversified effects on employment and skills. The richness of the dataset used in this study allows us to test the validity of such a perspective and main research hypotheses. In particular, it allows to account explicitly for the heterogeneity nature of digital processes and their differentiated effects across macro professional groups (High-skill, Medium-skill and Low-skill workers), different technological and productive contexts (manufacturing vs. service sectors; high- vs. lowtechnology sectors) and according to the different organizational environment in which digitalization takes place (routine vs. non-routine labour processes and tasks).

The paper is organized in four main sections. The next section locates this contribution within the existing empirical literature dealing with the employment effects of digitalization and routineness. Section 3 describes the data set and the indicators used in the empirical analysis. Section 4 shows descriptive evidence on the extent and the ways in which the level of digitalization of professions and industries are related to the level of routineness of labour processes and how both elements are related to the dynamics of employment across main industries and macro-professional categories. Section 5 contains an econometric estimation of the impact of digitalization and routineness on employment.

\section{Literature review}

Over the last three decades the pervasive role played by Information and Communication Technologies (ICT) has been investigated by a massive amount of theoretical and empirical research. A first stream of literature has tried to assess the economic impact of ICT on key performance variables such as output and productivity growth, at any possible level of aggregation (firms, sectors, regions and countries). The basic conceptual and methodological framework used to estimate the economic effects of ICT has been rooted in a neoclassical-type production function and on a rather narrow view of digitalization. Results and methodologies, as well as strengths and limitations of this first stream of literature, have been effectively synthesized by several reviews (OECD 2004; van Reenen et al., 2007). A more recent stream of literature has more specifically dealt with the employment implications of the paradigmatic change brought about by the digital era. The diffusion of Information and Communication Technologies, and more broadly "digital technologies", has in fact led to in-depth transformations in the organizational features of firms, industries, production processes, in consumption models and labour activities. More specifically, the 'computerization' and "digitalization" of workplaces and the associated changes in the organizational models and skill requirements of firms and industries have been recognized as key drivers of the asymmetric dynamics of employment and wages across high and low skilled labour, professional groups, routine and non-routine labour functions and tasks (for a review of the relevant literature, see Vivarelli, 2014).

Such asymmetric effects of ICT on employment have been analysed through the proposition of two key concepts and interpretive devices referring to the presence of a twin "bias" of these technologies in relation respectively to the skill-endowment of labour (Skill-biased technological change - SBTC) and the 
level of routineness of the task performed in the different occupations (Routine biased technological change - RBTC).

According to the SBTC hypothesis, digital technologies have differentiated effects on the marginal productivity of labour depending on the skill content and the level of qualification of the labour force. It is assumed that labour (or total factor) productivity gains can be obtained only if the adoption and use of ICT are complemented with qualified skills and competencies (Autor and Murnane 1998; Machin and Van Reenen 1998). The main argument is that skilled (i.e. educated) workers are more capable of learning how to use new technologies, and that they are more flexible with respect to their job assignment. The adoption of ICT often requires deep organizational changes, and firms with a high percentage of skilled workers can more easily and effectively implement information technologies. SBTC induces firms willing to exploit the opportunities offered by digital technologies to make larger use of qualified labour at the expenses of the low-skilled least-qualified component of the labour force. This would be the main explanation of the long-term compositional changes of employment observed in most industrialized countries over the last few decades and in particular of the increasing share of the highly educated and high-skilled component of labour force (Autor and Dorn 2009; Kemeny and Rigby 2012; Michaels et al. 2014).

Furthermore, the increase of wage differentials (more pronounced in the USA and UK than in continental Europe) has been associated to SBTC and to the increase in the demand of qualified labour which has not found in the labour market, and in the education system as whole, a corresponding capacity of supplying these new set of competencies (Krueger 1993; Spitz-Oner 2006; OECD, 2015). Despite the dispute about the skill-biased nature of ICTs has been the object of a lively debate, the empirical research produced so far seems to provide an overall support to the idea that the widespread diffusion of ICTs has contributed, along with other factors, to explain the long term asymmetric dynamics of employment and wages and that this asymmetric pattern is broadly associated to the level of skills and educational attainments of the labour force. There is also evidence that the new technological paradigm has contributed to generating new phenomena of economic and social exclusion (digital divide), negatively affecting old generations and digitally unskilled labour (Codagnone 2009). More in general, it has been shown that the access and ability to use ICT affects employability conditions along the entire long life cycle of individuals, being able to influence the decision to enter the labour market (the labour participation decision), the likelihood of getting a job (the transition from unemployment to employment) (Codagnone 2009), the likelihood of losing a job (the transition from employment to unemployment) (Friedberg 2003; Aubert et al., 2006) as well as decisions of early retirement (Schleife 2006).

Recently, theoretical appeal and interpretability of SBTC approach have somewhat faded in relation to the emergence of a new pattern in the dynamics of employment and wages: polarization. Polarization means that middle-class jobs (in terms of skills and wages) tend to be penalized relative to those belonging to high and low classes. This phenomenon has been detected in most - even if not all, advanced economies (Spitz-Oener, 2006; Autor and Dorn, 2009, 2013; Oesch and Rodriguez, 2011, Goos et al. 2014; Bogliacino and Lucchese, 2015; Fernández-Macías and Hurley, 2016; Cirillo, 2016; Eurofond, 2016; OECD, 2017). Looking at OECD data for Italy (our object of analysis), between 1995 and 2015 both high and low skill occupations experienced similar rates of growth: over 4.5\%. On the other side, middleskill occupations experienced a decrease of around 10\%. Most of the studies analysing this topic converged in recognizing ICT (together with the phenomenon of productive delocalization or 
'offshoring' mounting since the 1970s) as the major engine of the asymmetric labour market developments observed in the last decade. The flourishing of studies investigating the process of employment and wages polarization coincides therefore with the transition from an analytical approach concentrating their attention on technology and skills (SBTC) to an approach (RBTC) focusing on the very object of potential substitution by machines and ICT devices: "tasks" (Autor et al., 2003; Autor, 2013 and Autor and Dorn, 2013). The RBTC approach distinguishes jobs no longer on the basis of their generic 'skill endowment' but according to the relative share of routine tasks characterizing each of them. ${ }^{2}$ Particularly relevant for the research objective of this contribution is the potential relationship between the level of tasks routineness and the scope for digitalization and automation of labour processes, a key nexus for the RBTC hypothesis. In fact, in the seminal paper by Autor et al (2003) it is argued that computerisation enhances the possibility of automating tasks characterized by a high degree of routineness. This is because routinized tasks can be more easily codified (with respect to non-routine tasks) and therefore automated through the introduction of digital technologies. Routineness does not apply only to low qualified (manual) labour processes but also to cognitive tasks (carried out mainly by managers and professional workers). The latter can be therefore distinguished (as in the case of manual tasks) in routine and non-routine tasks. While non-routine cognitive tasks are likely to be linked to digital technologies by a complementary relationship, cognitive routine tasks (characterizing clerical and administrative professions) are potentially subjected to automated through the introduction of digital technologies (Autor et al. 2006).

Despite the conceptual and methodological difficulties in dealing with somewhat slippery and ambiguous categories such as "tasks" and "routineness" (Fernández-Macías and Hurley, 2016; Sebastian and Biagi, 2018), starting from the pioneering contribution of Autor et al. (2003) the literature on RBTC has rapidly expanded and produced results broadly supporting the validity of such an approach (Sebastian and Biagi, 2018). Making a systematic review of this large stream of empirical literature goes beyond the scope of this section. It is however worth highlighting two major traits of this literature that somewhat weaken the validity of its findings.

The first trait consists of assuming - in a deductive way - that changes in the compositional tasks of employment are the result of the above-mentioned differences in the (potential) applicability of digital technologies across tasks depending on their level of routineness. Such a nexus is most of the time simply assumed and much more rarely assessed empirically. In fact, only few studies have explicitly empirically assessed the routineness-digitalization nexus and used data and indicators (at the level of firms, industries or occupational groups) on both domains in order to assess their independent, or combined, effects on employment. $^{3}$

The second trait has to do with the conceptualization and measurement of digitalization. In most of the literature, digitalization is conceived as the mere acquisition or use of specific ICTs items (computers, software, internet, robots). Autor et al. (2003; 2013) and Michaels et al. (2014) take into account the role of investment in computer and IT capital; Acemoglu and Restrepo (2017), Graetz and Michaels (2017) and Dauth et al. (2017) assess the employment effects of the use of robots. Marcolin et al., (2016) use an

\footnotetext{
${ }^{2}$ It should be noted however that the skill content of jobs and the level of routinization of tasks are not independent from each other. Marcolin et al. (2016) find a significant negative correlations between the two.

3 The exceptions are Autor, 2003, Marcolin et al., 2016.
} 
ICT intensity indicator the proportion of workers employed in the business functions "ICT services" and "Engineering and related technical services" in a given industry, over the total industry. Data on a broader set of ICT related technologies (including Internet, intranet, broadband, home pages, services offered via home pages, electronic commerce, and electronic data interchange) are used by a study of Bockerman et al. (2018).

This narrow approach to digitalization and its impact on employment has largely been dictated by data constraints. In fact, finding a comprehensive and coherent set of indicators on a multifaceted phenomenon such as digitalization has proved to be a rather challenging task. Over the last 15 years Eurostat through its "Community survey on ICT usage and e-commerce in enterprises" has been collecting data on a rather broad array of ICT related activities carried out by firms and households. These data represent (potentially) a very rich information source to systematically assess the relevance and the economic impact of ICT at a macro, sectoral and even at a micro level. Unfortunately, the actual usability of these data for empirical research is much more limited. The access to microdata is severely restricted and the sectoral (and country) coverage of the data made publicly available by Eurostat is far from being complete. Other studies have tried to map the digital intensity of industries and countries combining internationally available data sources on ICT and digital activities (Guerrieri and Bentivegna, 2012; Calvino et al. 2018; McKinsey, 2015). A study coordinated by Guerrieri and Bentivegna (2012) has collected and merged data from the most relevant international data-sets on ICT and synthesised the latter into three composite indicators of digitalization broadly referring to the level of ICT infrastructure, the actual usage of internet services and the impact of these technologies and services in key socioeconomic domains and the associated process of digital empowerment. Following a similar methodology Calvino at al. (2018) have proposed a taxonomy of sectors according to "the extent to which they have gone digital" combining data on ICT tangible and intangible (i.e. software) investment, the purchases of intermediate ICT goods and services, the stock of robots, the number of ICT specialists and the share of turnover from online sales and also presenting an overall composite indicator of digitalization that synthesises the main ICT dimensions taken into account. The study shows the existence of a high sectoral heterogeneity of digital patterns but also the presence of very large (unexpected and difficult to explain) cross country (intra-industry) differences in the level of digitalization. The latter finding sheds some doubts regarding the robustness and reliability of the ICT indicators proposed and raises once again the issue regarding the quality and robustness of available data on digitalization. In choosing dataset and indicators scholars in this challenging area of research have in fact to find the best compromise with respect to two key data requirements: the ability of data and indicators to reflect the multifaceted and heterogeneous nature of digitalization in the different organizational and productive contexts in which they take place; the use of sufficiently robust and reliable data. This contribution has the ambition to use a dataset and a set of indicators on digitalization and routineness that fulfil both such requirements. It aims at contributing to the existing literature exploiting two major strengths of the CPI data-set: the possibility of measuring digitalization on the basis of very detailed information on the nature and digital content of labour activities and tasks; the possibility of assessing the independent and combined effect of digitalization and routineness on the dynamics of employment at a very disaggregated level of professional occupations. 


\section{Data and indicators}

Our empirical analysis is based on two major data sources providing information - at the occupation (4 digit)-sector (1 digit) level - on employment dynamics (plus a large set of labor market variables) and on task, skill, work attitudes, routine-task intensity, digital tasks and usage of digital tools. Employment and labor market variables stem from the Italian Labor Force Survey (ILFS) carried out by the Italian National Statistical Institute (ISTAT). The latter is the largest survey conducted in Italy to monitor the (quarterly) dynamics of the labor market. The ILFS provides information on employment, wages, workers sociodemographic characteristics (age, gender, educational status) and labor market institutions (share of workers with temporary contract). The sample includes more than 250.000 Italian households (for a total of about 600.000 individuals) distributed in about 1.400 Italian municipalities. The ILFS is based on a mixed CAPI-CATI strategy complying with the highest statistical standards in terms of sampling strategy and representativeness. The questionnaire includes a general section (reporting personal and family information) and 12 sections, from $\mathrm{A}$ to $\mathrm{N}$, each characterized by a specific information objective: A) respondents detail; B) employment status in the reference week; C) main job; D) secondary job; E) previous work experience; F) job search; G) employment services and employment agencies; $\mathrm{H}$ ) vocational education and training; I) self-perceived condition; L) detailed information on the family of the respondent; M) information provided by the interviewer; $\mathrm{N}$ ) pending codings (for a detailed description, see also Gualtieri et al. 2018). The ILFS provides high quality information on labor market dynamics. Among its major strength, there is its large sample size, the refined sampling strategy as well as the regulatory provisions according to which respondents are obliged to reply. The combination of these elements guarantees both data quality and representativeness. Moreover, the continuous reiteration of the ILFS survey allows ISTAT to periodically refine items and on-field strategy improve, wave-bywave, variables' quality. The ILFS covers the whole universe of Italian industries and occupations at the highest possible level of disaggregation (i.e. 5 digit). The variables selected for this analysis are the following: employment status, wages, socio-demographic characteristics (including age, gender and educational attainment), contract type (open-ended or temporary).

Data on task, skill, work attitudes, routine-task intensity, digital tasks and usage of digital tools stem from the INAPP-ISTAT Indagine Campionaria sulle Professioni (ICP). The ICP is a rather unique source of information on skill, task and work contents. In fact, the ICP is the only European survey replicating extensively American $\mathrm{O}^{*} \mathrm{Net}^{4}{ }^{4}$ The latter is the most comprehensive repertoire reporting qualitativequantitative information on tasks, work context, organizational features of workplaces at a very granular level. Both the American O*Net and the Italian ICP focus on occupations (i.e. occupation-level variables are built relying on both survey-based worker-level information as well as on post-survey validation by experts' focus groups). The ICP survey has been carried out twice (2007 and 2012) covering the whole spectrum of the Italian 5-digit occupations (i.e. 811 occupational codes). The interviews are administered to 16.000 Italian workers ensuring representativeness with respect to sector, occupation, firm size and

\footnotetext{
${ }^{4}$ The O*Net database builds upon the Dictionary of Occupational Titles (DOT, hereafter) which since 1939 reported information on occupations with a specific focus on the skills required in the public employment service. The $\mathrm{O}^{*} \mathrm{Net}$ is based on the SOC providing for each elementary occupation variables on knowledge, skills, abilities and tasks. The key dimensions included in the $\mathrm{O}^{*} \mathrm{Net}$ are the following: worker characteristics - permanent characteristics affecting workers performance as well as their propensity to acquire knowledge and skills; worker requirements - workers characteristics matured by means of experience and education; experience - characteristics mostly related to past work experience; occupation - a large set of variables referring to requirements and specific features of the various occupations.
} 
geographical domain (macro-regions). ICP information are collected relying on a 1-hour long CAPI interview administered at the workplace. On average, 20 workers per each Italian occupation are interviewed providing representative information at the $5^{\text {th }}$ digit. The survey includes more than 400 variables on skill, work contents, attitudes, tasks and many other subjective and objective information on occupations. ${ }^{5}$ More specifically, the ICP provides a massive amount of information concerning work contents and attitudes, skills and tasks, technological and organizational characteristics of productive processes, degree of standardization and control of workers operations, importance and nature of social interactions.

The empirical analysis presented in this paper builds upon a dataset having as statistical unit occupation (4 digit) -sector (1 digit) cells. ${ }^{6}$ We focus on long-term variation relying on 2011 and 2016 data. The occupation-sector correspondence is obtained by using a 4digit $\times 4$ digit occupation (row)-sector (column) matrix. The latter has been set relying on the ILFS micro data. To ensure representativeness of employment variables we opted for larger cells - i.e. 4digit (occupation) $\times 1$ digit (sector) - as opposed to those potentially available using in full the original matrix - i.e. i.e. 4digit (occupation) $\times 4$ digit (sector). The employment and labor market variables are computed by summing up ILFS individual-level employment data for each Italian $4^{\text {th }}$ digit occupation. ${ }^{7}$ The occupation-level variables on routine-task, digital tasks, use of digital tools and innovation (i.e. new products) are drawn from the last ICP wave (i.e. 2012) and are sector-invariant.

As a result, the full set of variables used for the empirical analysis at the $4 \times 1$ cell-level are the following. On the employment side (variables stemming from the ILFS): rate of change (logarithmic differences) of employment, share of female employees, share of young workers (15-34 years), share of workers with tertiary education, share of workers with temporary contract. Concerning tasks, digital tasks and usage of digital tools (variables stemming from the ICP): Routine Task Index (RTI) ${ }^{8}$ and its subcomponents (i.e. Routine Manual (RM), capturing the relative degree of manual routine tasks; and Routine Cognitive (RC), capturing the relative degree of cognitive routine tasks); Digital Use Index; Digital Tasks Index and Digital Skills Index. In addition, we include an ICP variable reporting information on the share of workers, by each 4-digit occupation, declaring that a process innovation occurred in their workplace. A

\footnotetext{
${ }^{5}$ The major difference between ICP and $\mathrm{O}^{*}$ Net regards the source of information on which the two survey rely. The ICP is based entirely on face-to-face interviews to job incumbents while the $\mathrm{O}^{*}$ Net relies on a mixed pool of job incumbents and labor analysts. It should be noted, however, that both ICP's waves has been followed by a continuous set of qualitative analysis (focus groups involving labor market experts and practitioners) aimed, among the other things, at periodically validate and maintain information stemming from job incumbents interviews. The ICP sample stratification strategy has two steps. First, a large number of companies is randomly selected (the public administration is not included). Once the company-level sample is selected, questionnaires are submitted via Computer Assisted Personal Interviewing (CAPI) techniques to workers.

${ }^{6}$ We cannot rely on cells with a higher level of disaggregation at the sectoral level due to risks concerning statistical representativeness of employment and labor market variables.

${ }^{7}$ For each 4-digit occupation we computed the total number of employees; total number of employees by gender, age, educational attainment, type of contract.

${ }^{8}$ To measure the relative routineness of tasks characterizing our 4-digit occupation we rely on the RTI proposed by Autor et al. (2003). Having at our disposal a database overlapping (in terms of items' contents and scale) the US O*Net we are able to build the RTI following precisely the Autor et al. (2003)'s procedure. This element represents an advancement as compared to what is done in the literature on job polarization (i.e. the literature referring to the Routine Biased Technological Change hypothesis) focusing on Europe. In order to capture the relative routineness of occupations and sectors, these studies impute, via a SOC-ISCO crosswalk, the US O*Net variables' values to European occupations. This of course introduces a bias given the significant differences characterizing the US vis-à-vis the European occupational structure (for an extensive discussion on this point, see Gualtieri et al. 2018).
} 
synthetic description of the adopted variables (specifying contents, source, time and scale) is provided in table 1.

Table 1: List of variables and sources used in the analysis

\begin{tabular}{|c|c|c|}
\hline Variables & Description & Source \\
\hline Labor market variables & & RCFL \\
\hline $\begin{array}{ll}\text { - } & \text { Total employment } \\
\text { (thousands) } \\
\text { - } \\
\text { - } \text { Yomen }(\%) \\
\text { - Share of temporary } \\
\text { contracts }(\%) \\
\text { - Share of part-time } \\
\text { workers }(\%)\end{array}$ & $\begin{array}{l}\text { - Employees by 4-digit occupation/1-digit ATECO sector } \\
\text { - Share of women (employees) over the total by 4-digit } \\
\text { occupation/1-digit ATECO sector } \\
\text { - Share of 15-34 years old employees over the total by 4-digit } \\
\text { occupation/1-digit ATECO sector } \\
\text { - Share of workers with temporary contracts over the total } \\
\text { by 4-digit occupation/1-digit ATECO sector } \\
\text { - Share of workers with part-time contracts over the total by } \\
\text { 4-digit occupation/1-digit ATECO sector }\end{array}$ & \\
\hline Task-related variables & & ICP \\
\hline $\begin{array}{l}\text { RTI index and } \\
\text { subcomponents } \\
(0-100)\end{array}$ & $\begin{array}{l}\text { - Dimensions comprised in the RTI by 4-digit occupation } \\
\text { (see table } 2 \text { for details) }\end{array}$ & \\
\hline Digital related variables & & ICP \\
\hline $\begin{array}{ll}\text { - } & \text { Digital Use }(0-100) \\
\text { - } & \text { Digital Tasks }(0-100) \\
\text { - } & \text { Digital Skills }(0-100)\end{array}$ & $\begin{array}{l}\text { - Dimensions comprised in the Digital Use, Digital Tasks } \\
\text { and Digital Skills indicators (see tables } 3 \text { and } 4 \text { for details) }\end{array}$ & \\
\hline Innovation related variables & & ICP \\
\hline - Process innovation $(\%)$ & - Incidence of process innovation by 4-digit occupation & \\
\hline
\end{tabular}

\section{The Digital Use Index}

We develop a digital use index to measure how often and at which level of complexity workers in any professional group interact with digital technologies. Much as "routineness" takes different meanings depending on the occupations, firms, and industries, the level of digitalisation should be measured consistently across profession. We thus develop a composite indicator based on three questions from the ICP survey. From the section of the survey devoted to "General workplace activities" we select two questions that measure the level of complexity with which professionals report using digital and information technologies, namely:

1. (Q. G19) "Working with computers": described as "Using computers and information systems (software and hardware) to program, write software, manage functions, input data, or process information."

Responses are reported on a 1-7 Likert scale, with the following benchmarks of complexity levels:

- 2: Input employee data on a digital database

$\circ$ 4: Develop an inventory management software 
○ 6: Develop an IT system for a large multinational

2. (Q. G24) Documenting and recording: To input, transcribe, record, archive or store information in on a written, magnetic or electronic medium.

The benchmarks for complexity are:

○ 2: Record the cargo freight traveling on a highway

- 4: Documenting results of a crime scene investigation

○ 6: Store satellite use data for a private telecommunications company

(In both cases, the benchmarks are meant to be contextualised by the interviewer based on the relevant profession and industry of the interviewee.)

3. (Q. H2) Using e-mail as part of one's occupation

The third question, from the section of "Working conditions" simply asks respondents how often they use e-mail as part of their work. As a ubiquitous means of communication - but by no means universally adopted - it serves as a useful indicator of digitalisation of the workplace.

Each of these questions acts as an informative indicator of different aspects of digitalization of work, in its organisational context. For each of professional group, we observe the normalised score of all three responses expressed in a [0-1] scale, and then average them into the digital use index.

\section{The Digital Skills Index}

This index captures the level of knowledge that professionals have about concepts related (or adjacent) to digital technologies. This is a way to assess the ability of employees to understand the background and details of technologies and possibly harness technological change to their advantage.

Responses are again reported on a 1-7 Likert scale, with benchmarks of complexity levels.

1. (Q. B9) Informatics and electronics: Knowledge of electronic circuits, processors and chips in electronic devices, including knowledge of software package and applications

$\circ$ 1: Operating a DVD or CV

- 3: Using a word processor

○ 6: Developing an anti-virus software

2. (Q. B31) Telecommunication: Knowledge of radio transmission, broadcast, and connection and management of telecommunication systems

$\circ$ 1: Making a phone call

- 2: Installing a satellite antenna

- 7: Developing a new worldwide telecommunication system

3. (Q. C6) Sciences: Applying scientific rules and methods to solve problems.

- 2: Executing a test to determine soil quality

○ 4: Tests products for safety, following instructions

- 6: Analyse aerodynamic systems to assess the feasibility of an airplane design

4. (Q. C18) Operation analysis: Analysing characteristics and requirement of the necessary tools, services or products for project development

$\circ$ 2: Choosing a photocopy machine for the office

○ 4: Suggesting software changes to improve user experience

- 6: Identifying the necessary control system for a new production line

5. (Q. C19) Technological design: Developing or adapting tools and technologies responding to user demands 
- 2: Adapting gym equipment to the exercises of a client

$\circ$ 4: Redesigning a tool handle to improve grip

○ 6: Developing a new technology to manufacture diamonds

6. (Q. C22) Programming: Writing compute programs for various purposes.

- 2 Writing a program in Basic to sort entries in a database

- 4 Writing software for statistical analysis

- 6 Writing software for geological data analysis of a ground radar to survey mineral deposits

\section{The Digital Tasks Index}

To better capture the different ways work tasks are digitised, we develop a separate indicator based on the precise tasks (or activities) that characterize each profession. The ICP survey contains a free-form section where a panel of respondents from each of the 796 5-digit ISCO groups describe - mainly their own words, in a lightly coordinated manner - up to 15 work activities that best describe their occupation. For each of these tasks, there is a score indicating its importance.

This section of the ICP survey thus describes over 6200 distinct activities across all profession - after accounting for some activities practiced by different professions. After careful selection, we identify 131 activities that involve digital technologies and are indicative of a digital occupation. These are reported in Table A4 in the Appendix.

The list allows to derive a digital activities index for every profession: among the different activities enumerated by each profession, we sum the reported importance score of the digital ones, defined as being among those in Table A4. Compared to the digital use index, this one provides a more precise measure of intrinsic digitalisation of task contents characterising professions. However, it is also more restrictive, because it can only consider the digitalisation of the core tasks of the profession itself, and it is therefore less able to capture if ancillary professional activities are digitised or not.

\section{The Routine Task Intensity Index}

In line with Goos et al. (2014), we measure the degree of task routineness relying on the Routine Task Intensity (RTI) index. Taking advantage of the ICP questionnaire, we account for the same task-related dimensions considered by Autor et al. (2003) and followers in their empirical analysis. In our case, however, we go a step further than Goos et al. (2014) since our task and skill variables are directly referable to the Italian economy. In fact, the availability of ICP variables shields us from potential methodological problems arising when information referring to the American occupational structure (i.e. stemming from the US O*Net repertoire) are matched (i.e. by means of the SOC-ISCO crosswalk) to labor market data referring to significantly different economies as the European ones. As in Autor et al. (2003 pp: 1298), we build upon five dimensions allowing to qualify jobs according to their relative routineness. The RTI includes three dimensions (two referring to the degree of manual and cognitive task routineness, the other to the degree of 'non-routineness' of tasks) resulting from the combination of the five DOT dimensions considered by Autor et al. (2003). The detailed component of the RTI we use in this analysis are reported in table 2 The RTI adopted here is significantly close to the one in Autor and Dorn (2013) and Goos et al. (2014) and can be formalized as follows:

$$
R T I_{k, t}=R C_{k, t}+R M_{k, t}-\left(N R C A_{k, t}+N R C I_{k, t}+N R M_{k, t}+N R M I A_{k, t}\right)
$$


Where for each 5-digit occupation $\mathrm{k}(\mathrm{k}=1, \ldots, 811)$ and ICP wave $\mathrm{t}(\mathrm{t}=2007,2012)$ the RTI index is computed as the sum of the standardized values of the Routine Cognitive (RC) indicator capturing dimensions as the degree of repetitiveness and standardization of tasks as well as the importance of being exact and accurate; Routine Manual (RM) indicator proxying the degree of repetitiveness and of predetermination of manual operations minus the Non Routine Cognitive Analytical (NRCA) reporting the relevance of tasks related to think creatively as well as to analyse and interpret data and information; Nonroutine Cognitive Interpersonal (NRCI) referring to the importance of social relationships, interaction, managing and coaching colleagues; Non Routine Manual (NRM) capturing the degree of manual dexterity needed to perform operations; Non Routine Manual Interpersonal Adaptability (NRMIA) referring to degree of social perceptiveness. The indicator in (1) rises with the importance of routine task in each 4digit occupation while declines with the importance of abstract and non-routine tasks.

Table 2: The Routine Task Intensity Index

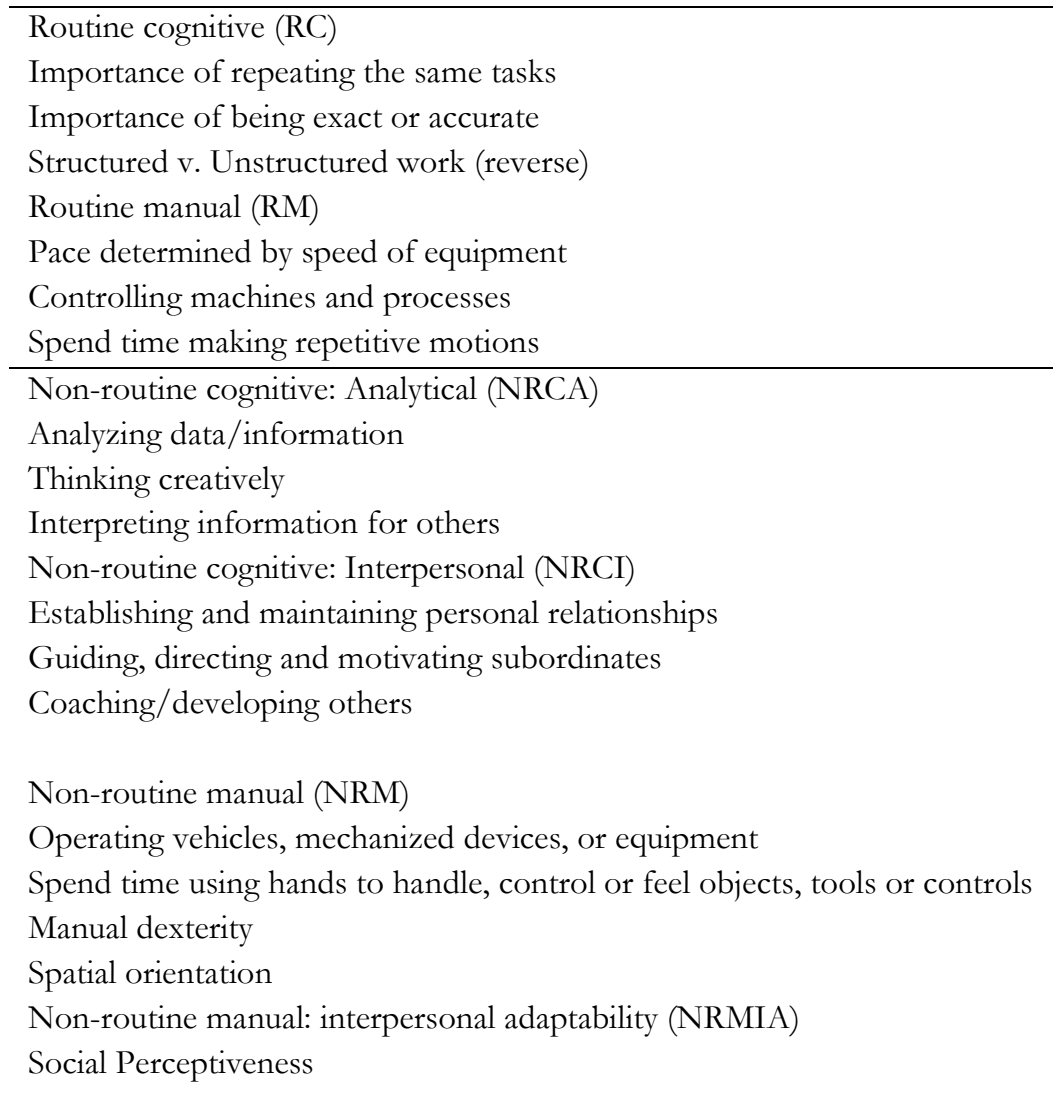

\section{Descriptive evidence}

In this section, we provide descriptive evidences on: a) the levels of digitalization and routineness of labour activities across industrial sectors and professional groups (High, Medium and Low-Skilled); b) the relationship between the level of digitalization and routineness of labour activities; c) the dynamics of employment in professions characterized by different levels of digitalization and routineness. 
Digitalization and routineness across macro sectors (manufacturing and services)

Figure 1 shows the levels of digitalization in manufacturing and service industries distinguishing three different measures of digitalization: "Digital Use", "Digital Tasks" and "Digital Skills". The same information at a finer level of sectoral breakdown is provided in the appendix (Figures A1, A2 and A3). Figure 1 shows that services are more digitalised than manufacturing industries for what concern the "digital use" indicator, while manufacturing shows an higher score for "digital skills". The two macrosectors show similar levels of digital tasks. In the service industries the level of digitalization is particularly high in communication and information activities and in the financial sector (Figures A1, A2 and A3 in the appendix).

Figure 2 shows the overall average scores of routineness (RTI index, i.e. the share of professions with high scores in routineness) across macro-sectors, and distinguishing between the level of routineness in cognitive tasks (Routine cognitive) and in manual tasks (Routine Manual). In the manufacturing sector the overall level of routineness is higher (less than 10\%) than in services and the same occurs for the share of routine cognitive and routine manual tasks $(15 \%$ higher in manufacturing with respect to services).

Figure 1: Digital Use, Digital Tasks and Digital Skills by macrosector
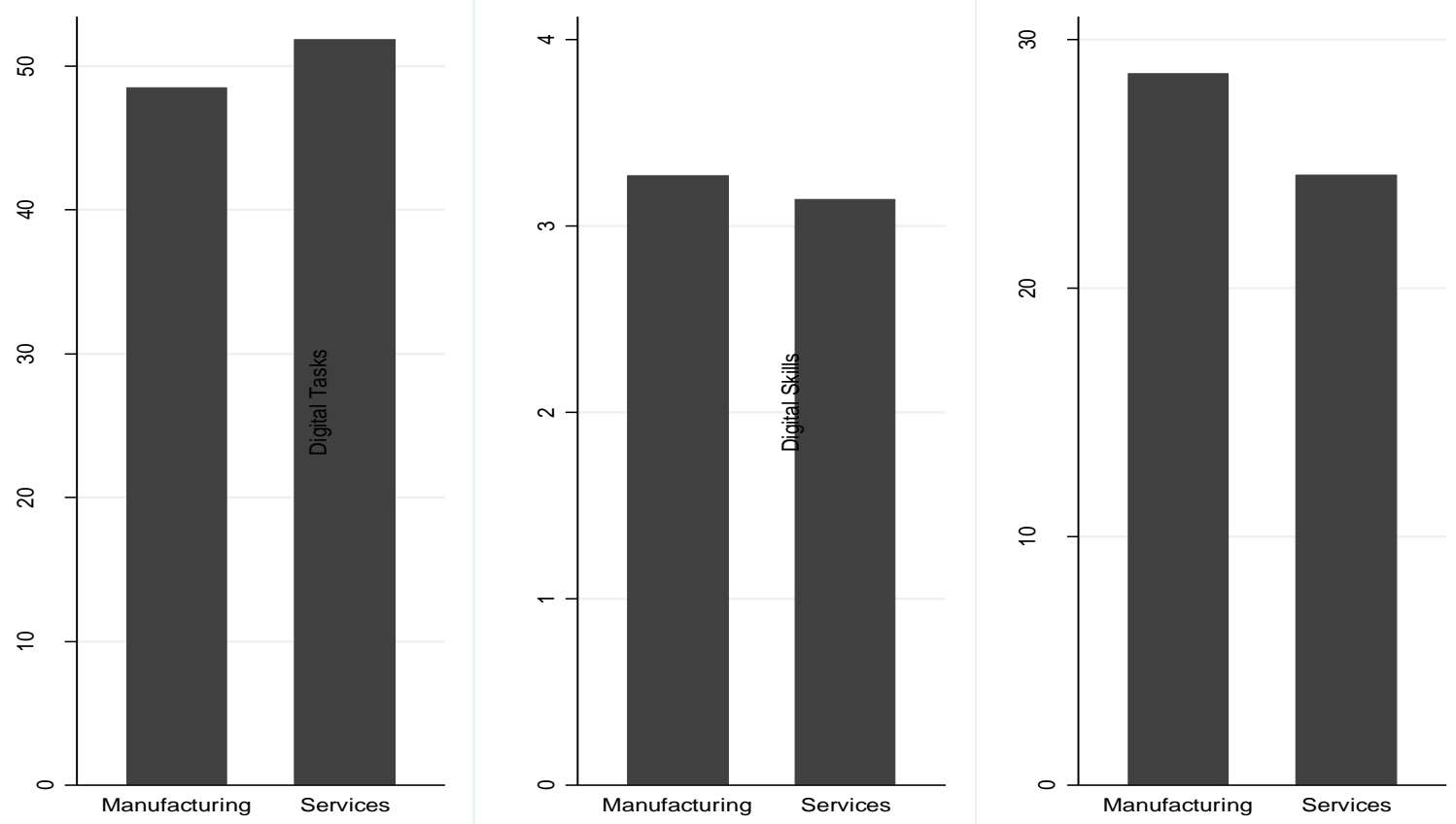

Note: Average scores of digital indices are weighted by number of employees in 2011 (LFS survey). 
Figure 2: Routine indexes (RTI, Routine Cognitive and Routine Manual) by macrosector
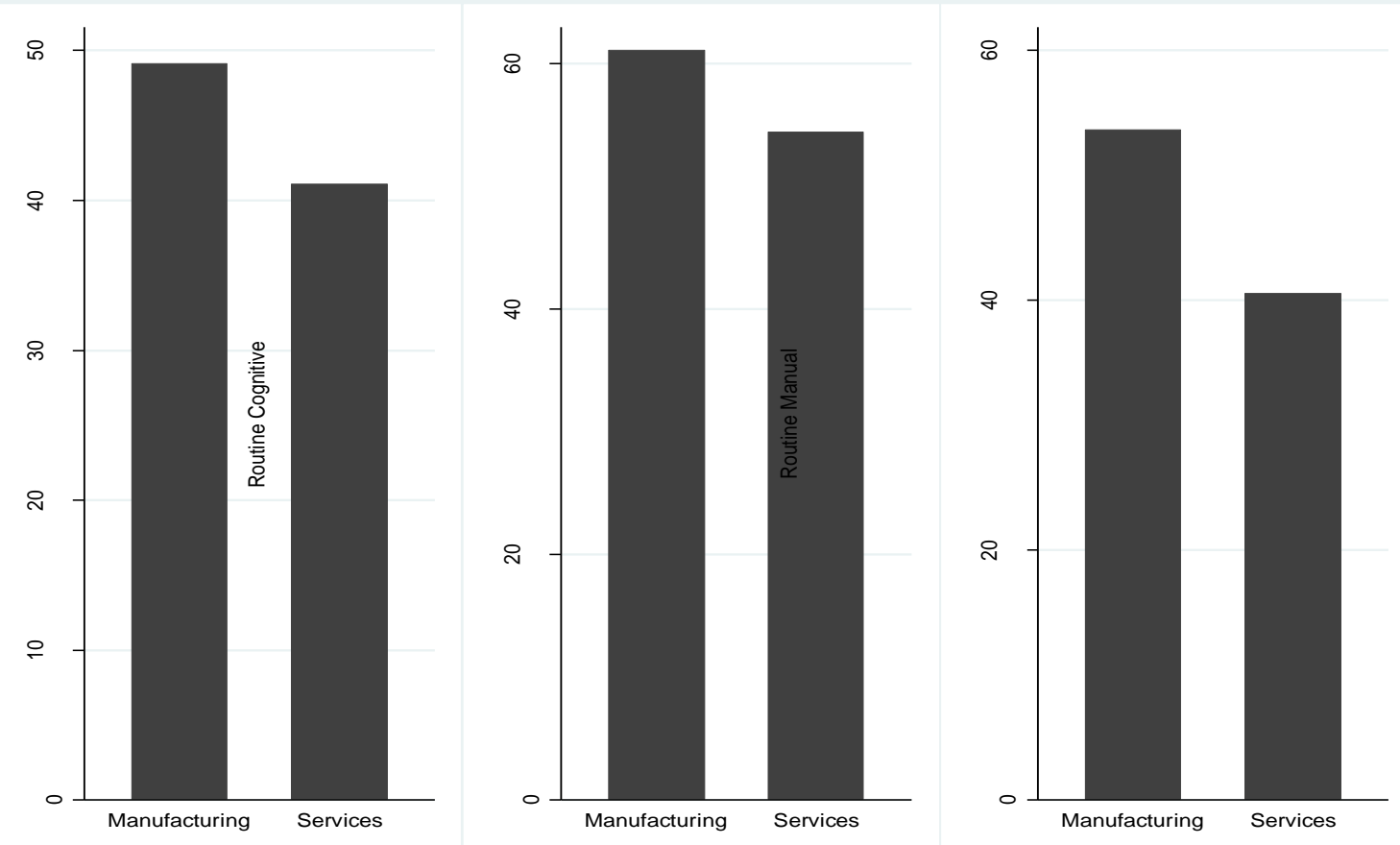

Note: Average scores of routine indices are weighted bynumber of employees in 2011 (LFS survey).

\section{Digitalization and routineness across skills (ISCO groups)}

The level of digitalization is expected to vary not only across industry but also across professional groups and the skill level of labour. In order to explore such source of heterogenity in digitalization we have grouped professions into three main borad occupational classes: the first group, defined as "HighSkilled", is composed by the first three ISCO professions - Managers, Associate Professionals and Technicians; the second group defined as "Medium-Skilled" refers to Clerks, Service, Sales workers and Craft workers; the third group, labelled as "Low-Skilled", includes Plant and machine operators and those performing elementary occupations (for a detailed description see table A1 in the Appendix). Figure 3 shows the presence of a monotonic distribution of digital scores with respect to the skill level of the three professional classes: High-Skilled professions show the highest scores in the case of all three digital idicators while Low-Skilled professions are the least digitalized. The digital divide across skills is particularly relevant in the use of digital devices while it is lower in the case of digital tasks and digital skills. 
Figure 3: Digital Use, Digital Tasks and Digital Skills by Skills (ISCO macrogroups)
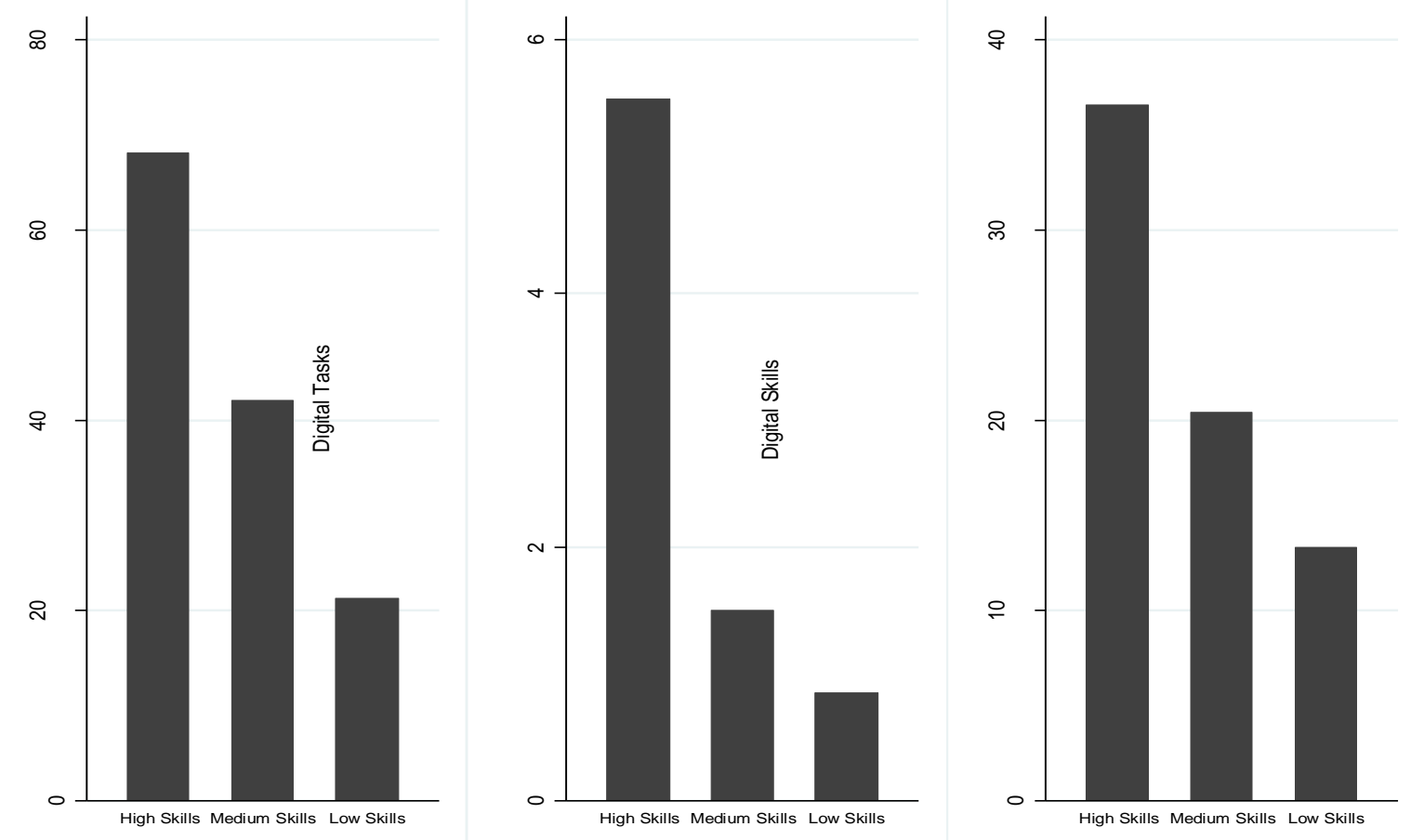

Note: Average scores of digital indices are weighted by number of employees in 2011 (LFS survey).

Skills and routineness are on the contrary linked by an inverse relationship. Figure 4 shows in fact that High-Skilled professions are characterized by a low share of routine activities - both cognitive or manual - while Medium and Low-Skilled show a relatively higher share of routinized tasks. The message comining from a joint examination of Figures 3 and 4 is that on average routineness does not go hand in hand with digitalization at the occupational level. High skilled professions are highly digitalized and are characterized by performing low routinary tasks, while the opposite pattern holds for medium and low skills jobs. 
Figure 4: Routinization by Skills (ISCO macrogroups)

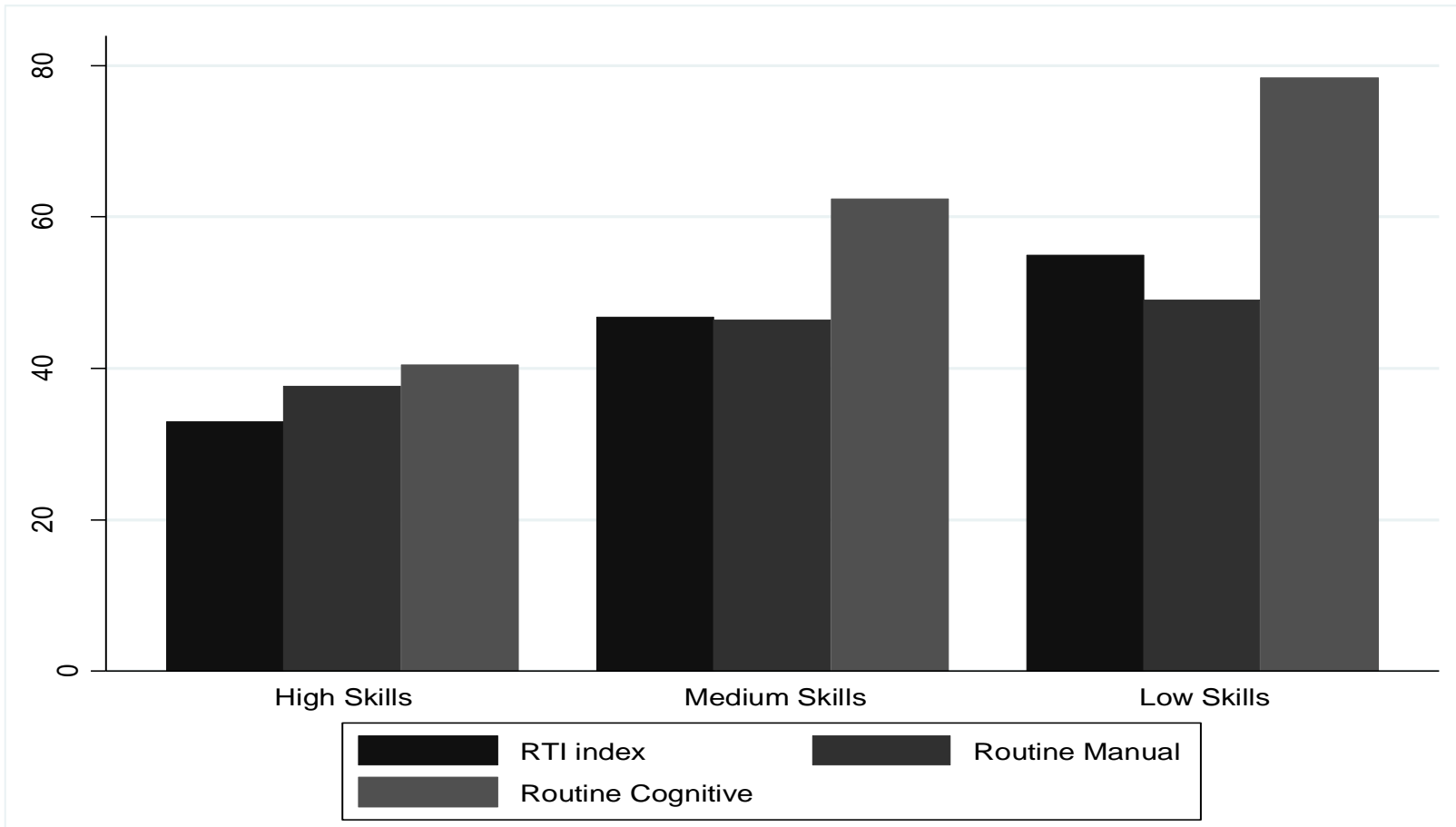

Note: Average scores of routine indices are weighted by number of employees in 2011 (LFS survey).

As a further step in the descriptive analysis, we show in Figure 5 the correlation among the full set of our digital and routine variables (Digital Use, Digital Tasks, Digital Skills, Routine Manual, Routine Cognitive and Routine Index - with the latter being positively correlated with the Routine Manual and Routine Cognitive index by construction). The matrix below highlights two major points. First, both digital and routine variables display positive and significant correlation with each other and this confirm the overall consistency and robustness of our digital and routine indicators. More interesting are the relationships existing between the two groups of indicators. As already mentioned in section 2 most of the literature assumes the existnece of a positive relationship between the level routiness of tasks and the possibility for these tasks to be digitalized. In most of the cases routineness and digitalness are considerd as sinonimous. The evidence emerging from our data-set shows that the level of digitalization of professions is on the contrary negatively correlated with their level of routineness. Professions displaying a high score in terms of digital use are poorly cognitively routinized. Also those professions displaying high scores in digital skills are poorly routinized. The correlation matrix shows only a weak positive correlation between the level of digital tasks and the level of manual routiness of professions. The presence of a negative relationship between the level of digitalizition and routineness emerging from our analysis is likely to be the result of the fact that both digital competencies and the use of digital devices are usually associated to more qualified and knowlde intensive professions and labour activities (that we have already seen being less routinary in nature). 
Figure 5: Correlogram of digitalization and routineness indices

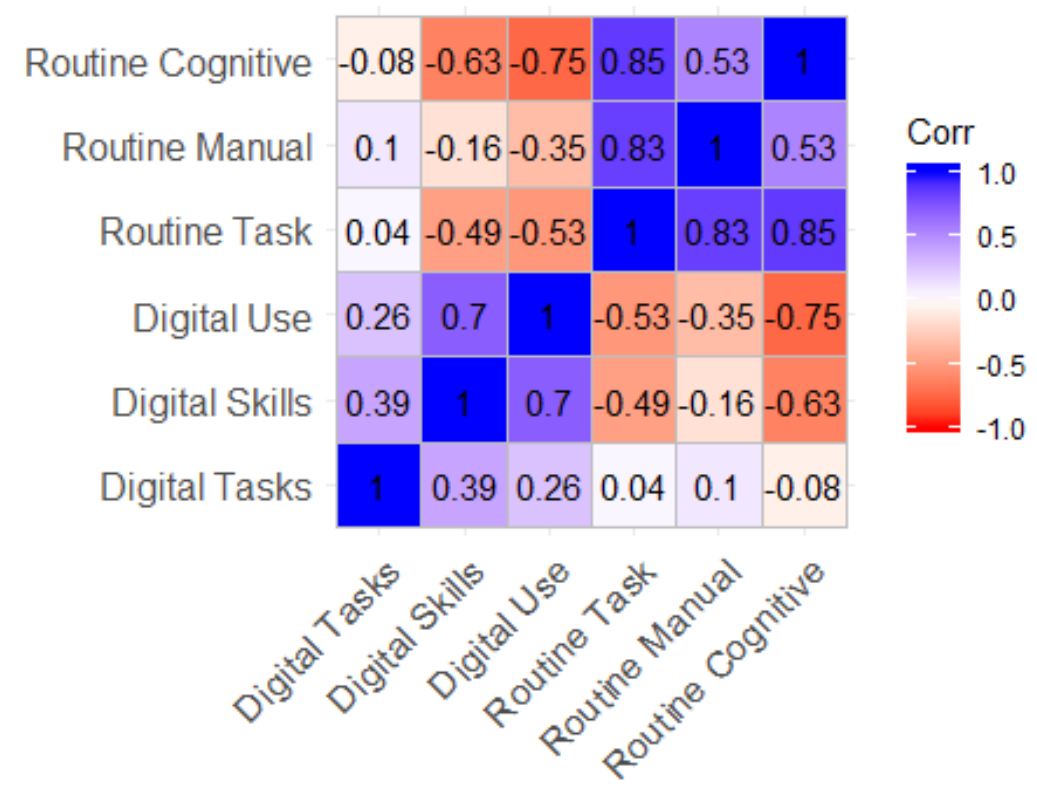

\section{Linking digitalization and routineness to employment changes}

The descriptive evidence presented so far has shown the presence of marked differences in the level of digitalization and routineness acrsoss sectors and professional groups. The following issue we want to investigate is what kind of realtionship exists between these two key dimensions of labour activities and the dynamics of employment. Figure 6 shows the rates of chage of employment (in the 2011-16 period) of the High-Skilled, Medium and Low-Skilled professional groups, and separately for manufacturing and service industries. In the period examined, in both macrosectors a pattern of job polarization seems to have occurred. In particular Figure 6 shows a strong contraction of medium skilled jobs in the manufacturing sector $(-10 \%)$, whereas in the service sector a positive employment dynamics occurs in all three professional groups, with the best employment performances found among the low skilled professions (more than 10\% growth rate). The large expansion of low skilled jobs in services probably reflects the specific profile of the the Italian tertiary sector. 
Figure 6: Employment rate of change by Skills (ISCO macrogroups) and macrosectors (2011-16)

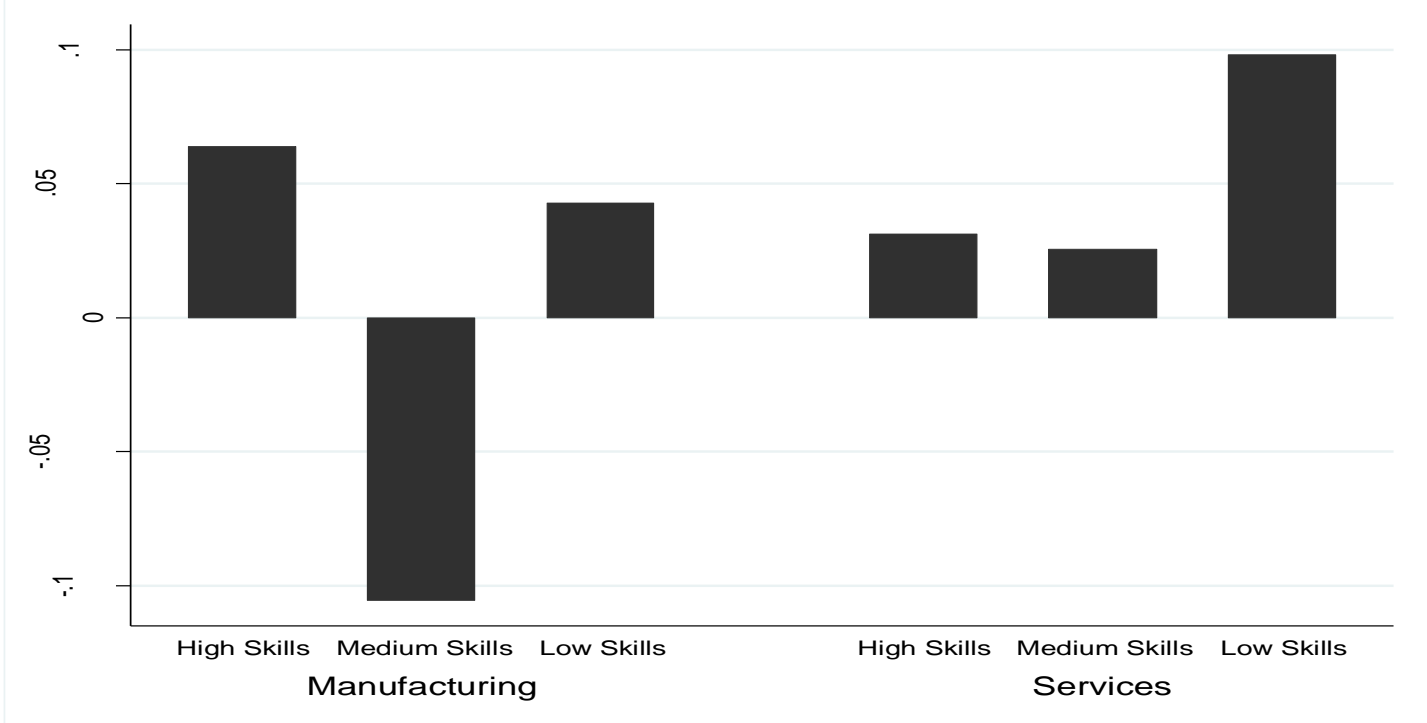

Are the different dynamics of employment shown in Figure 6 related to digitalization? Figure 7 allows us exploring this issue (although on a purely descriptive way) showing the rates of change of employment jointly by macro-sectors and according to the level of digitalization of labour processes. The level of digitalization is computed on the basis of the quantiles of the distribution (across professions) of our digital use indicator. Professions are accordingly divided in three main groups: "Low Digital Use" corresponding to those professions whose digital score is below the $25 \%$ of the digital score distribution; "medium digital use" that is those in the middle of the distribution (between 25\% and 75\%); "High Digital Use" those above the $75 \%$. Figure 7 shows rather different employment patterns in the manufacturing and service industries. In the manufacturing sector the professions classified as "Medium Digital Use" are those experiencing the heaviest job losses whereas in the service sectors employment has grown mainly among the least digitalized professions (more than $5 \%$ in 5 years). Once gain the strong expansion of low digitalized jobs in service sector shown in Figure 7 is the result of the rapid growth in Italy of low innovative and low value-added service industries. This pattern is somewhat confirmed in Figure 8 showing the dynamics of employment by professions classified according to our "Digital Tasks" indicator?.

A completely different picture emerges when we analyze the rates of change of employment in professional groups characterized by different levels of digital skills (Figure 9). In manufacturing, professions with the highest score in digital skills are the only ones growing over the period 2011-16 whereas professions with medium and low digital skills have experienced major job contractions. In services, both high and low digital professions (in terms of digital skills) have experienced job growth, while the professions characterized by a medium level of digital skills experienced a $2 \%$ loss of employment over the period. Figure 9 seems to suggest the presence of a pattern of digitally-related polarization in services, while a digital up-skilling is detected in manufacturing.

\footnotetext{
${ }^{9}$ For the "Digital Tasks" variable, occupations are classified in two groups: "Low Digital Tasks" and "High Digital Tasks" given the negative skewness of the distribution of the "Digital Tasks" indicator. The median of the "Digital Tasks" indicator is zero, therefore we only consider values below the median "Low Digital Tasks" and above the median "High Digital Tasks". The same holds for Table A2 in the Appendix.
} 
Figure 7: Employment rate of change by level of digitalization (digital use) and macrosectors (2011-16)

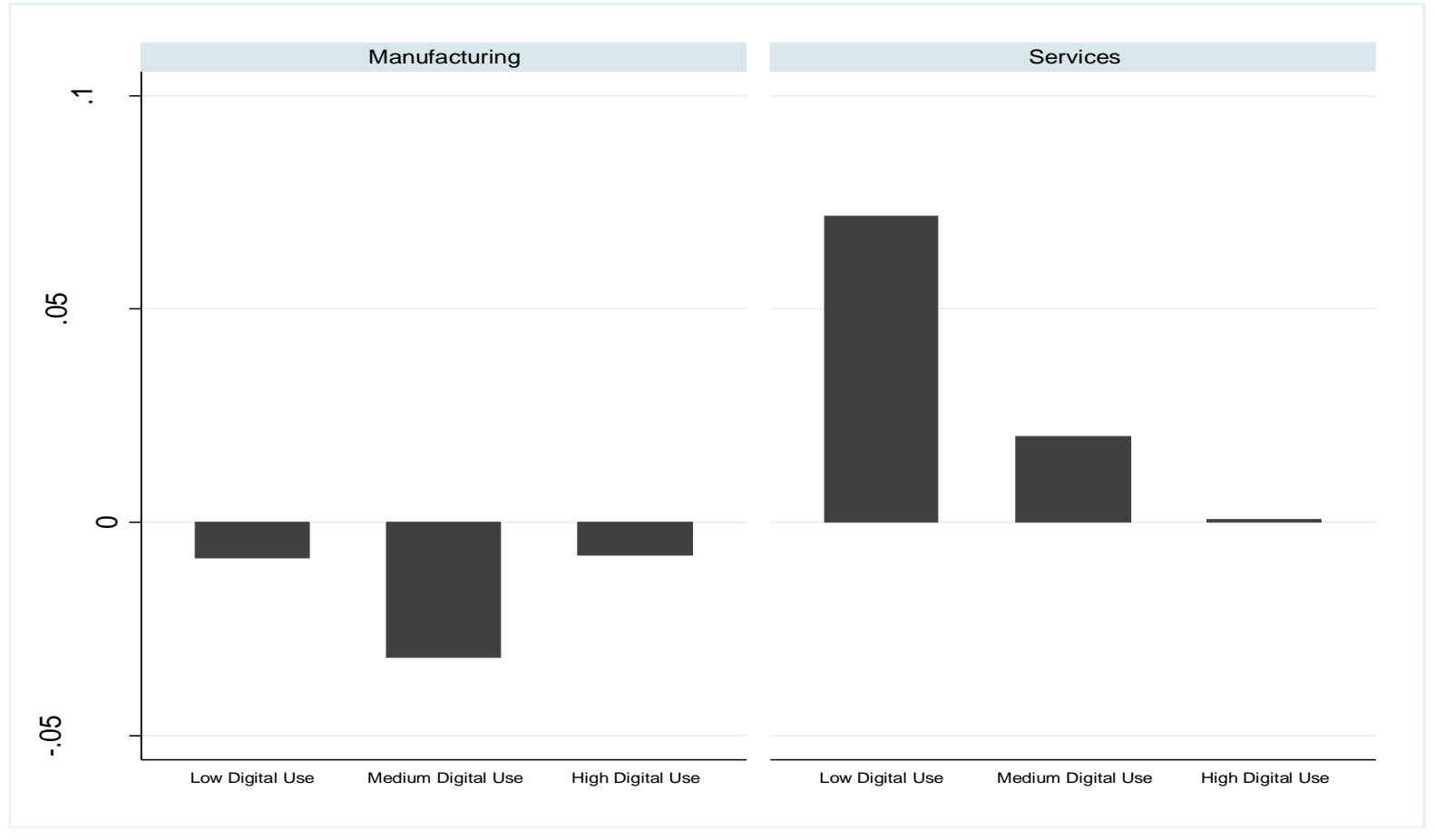

Figure 8: Employment rate of change by level of digitalization (digital tasks) and macrosectors (201116)

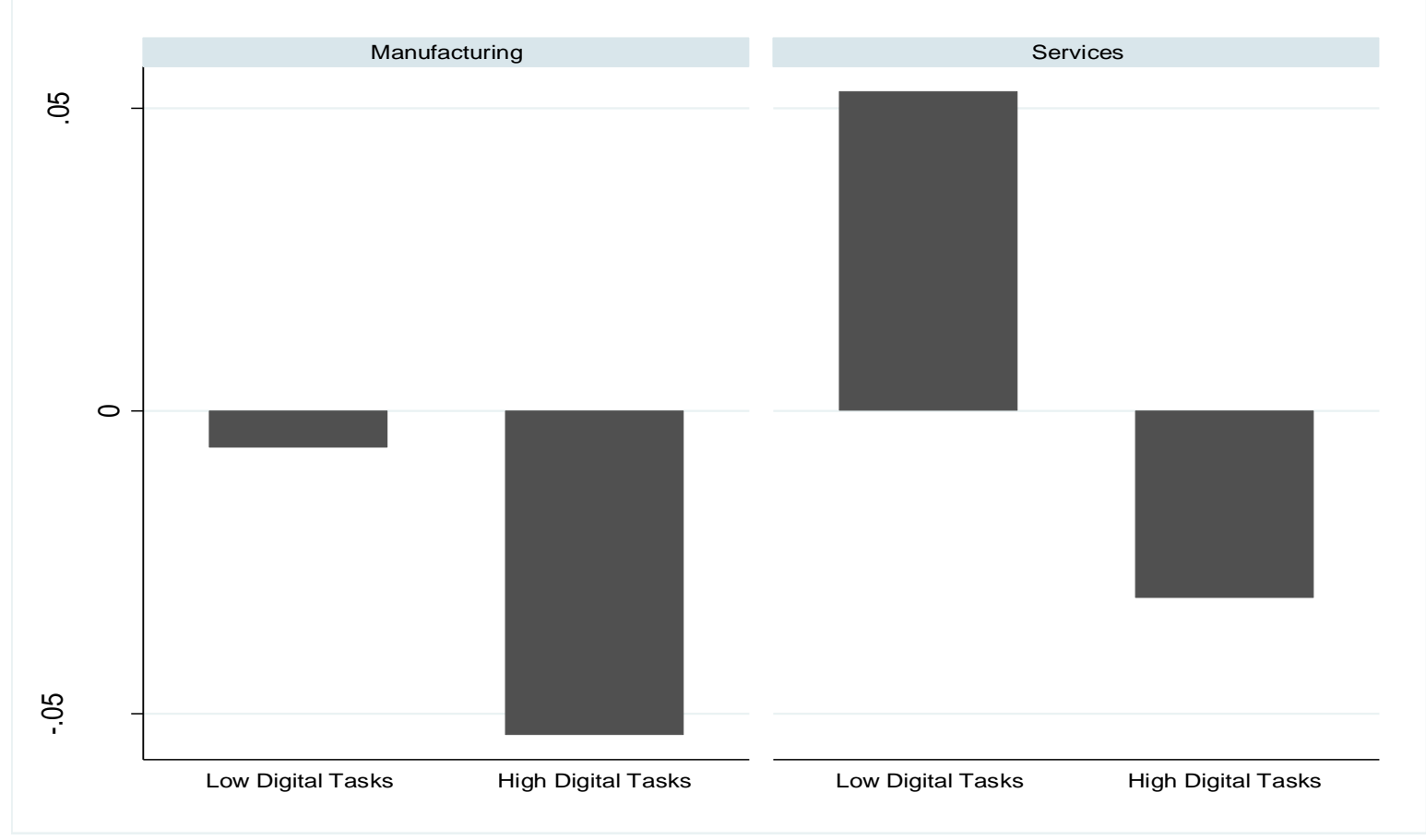


Figure 9: Employment rate of change by level of digitalization (digital skills) and macrosectors (2011-16)

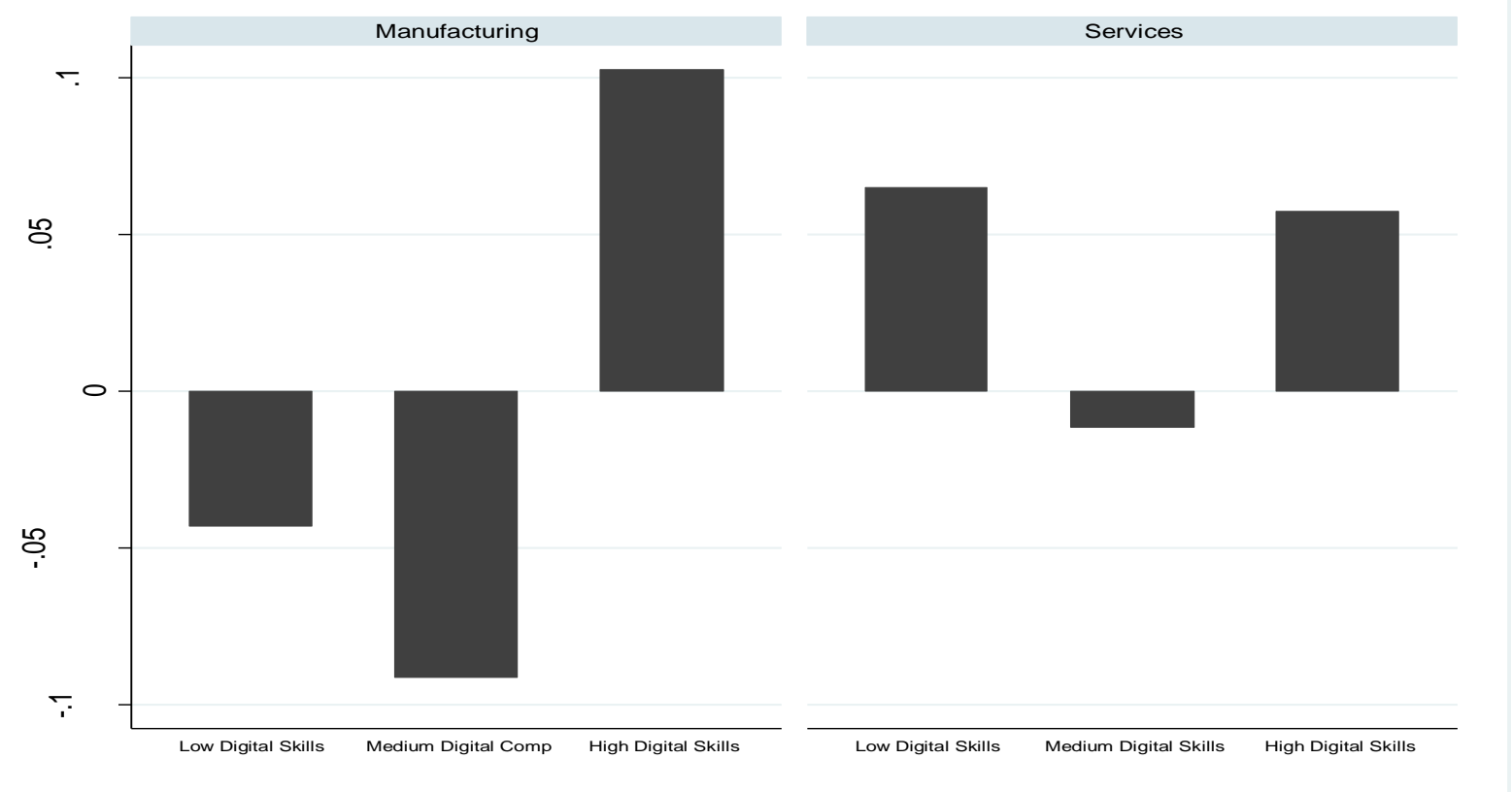

In Table 3 we explore the dynamics of employment jointly by the level of digitalization and routineness of professions. We compute the average rates of employment growth over the 2011-2016 period focusing simoultaneously on the two distributions referring the the levels digitalization and routineness of occupational professions. We aim therefore at addressing - using simple descriptive statistcs - the following two issues: Have highly routinized tasks experienced a faster job contraction in line with the literature $a$ la Autor and Dorn (2013)'? What is the combined effect of digitalization and routineness on employment?

Table 3 shows that the professions registering the greatest job contraction $(-16 \%)$ are those characterized by a high level of digitalization and routineness. A low level of digital use is associated with a positive job growth $(2.87 \%)$. A negative employment dynamics has been experienced by professions characterized by medium and high levels of digital use (-0.17\% and - $0.56 \%)$ and low and high levels of routineness (RTI) ($0.81 \%$ and $-0.90 \%)$. A strong positive dynamics of employment $(5.32 \%)$ is found only in those professional groups characterized by a medium level of routineness. Table 3 clearly the greatest job losses are found in professions combining high levels of both digitalization and routineness. A similar pattern is found when we look at the combined employemnt effect digital tasks and routiness (see table A2 in the Appendix).

Table 3: Rate of employment change by routineness and digitalization of professions

(Digital Use)

\begin{tabular}{l|ccc|c} 
& \multicolumn{3}{|c|}{$0.25>$ DIGITAL USE } & \\
\hline RTI $<0.25$ & DIGITAL USE $<0.25$ & $<0.75$ & DIGITAL USE $>0.75$ & \\
$0.25>$ RTI $<0.75$ & $2.19 \%$ & $-4.70 \%$ & $5.97 \%$ & $-0.81 \%$ \\
RTI $>0.75$ & $4.98 \%$ & $7.29 \%$ & $3.49 \%$ & $5.32 \%$ \\
\hline & $1.92 \%$ & $-2.37 \%$ & $-16.15 \%$ & $-0.90 \%$ \\
\hline & $2.87 \%$ & $-0.17 \%$ & $-0.56 \%$ & $1.24 \%$
\end{tabular}


A different scenario emerges when we focus on digital skills and on their relation with routineness and employment. On average digital skills seem to be associated to job growth (third column in table 4) and this even when professions are characterized by a high level of routineness $(5.8 \%)$. Conversely, major jobs contraction $(-10.5 \%)$ occurs in professions characterized by medium digital skills (positioned in middle of the distribution) and high level routineness.

Table 4. Rate of employment change by routineness and digitalization of professions (Digital Skills)

\begin{tabular}{l|ccc|c} 
& DIGITAL & $0.25>$ DIGITAL & DIGITAL SKILLS & \\
& SKILLS $<0.25$ & SKILLS $<0.75$ & $>0.75$ & \\
\hline RTI $<0.25$ & $-8.02 \%$ & $-5.70 \%$ & $7.46 \%$ & $-0.81 \%$ \\
$0.25>$ RTI $<0.75$ & $8.48 \%$ & $3.64 \%$ & $1.95 \%$ & $5.32 \%$ \\
RTI $>0.75$ & $1.65 \%$ & $-10.56 \%$ & $5.88 \%$ & $-0.90 \%$ \\
\hline & $2.66 \%$ & $-3.46 \%$ & $5.36 \%$ & $1.24 \%$
\end{tabular}

\section{Empirical strategy: rationale and results}

Following the descriptive exploration provided in the previous section, we now investigate, econometrically, if and to what extent the degree of 'workplace digitalization' might help explaining changes in employment at the occupation-industry level. We empirically operationalize some of the arguments put forth by Braverman (1974) and, more recently, by Fernandez-Macias and Hurley (2016). According to these authors, workplace digitalization takes place when companies envisage room of manoeuvre to increase efficiency (via the introduction of new digital tools and/or the digitalization of existing processes and tasks) by rationalizing workers' tasks, increasing monitoring, reducing bottlenecks and tracking errors along the production process, easing knowledge extraction, facilitating communication and favouring cooperation among workers. In this perspective, digitalization is expected to occur when specific technical (i.e. availability of digital technologies and tools) and work-content related conditions (i.e. tasks that are apt to be standardized, encoded and tracked digitally when they are performed) are both verified. For workplace digitalization to unfold - with its potential consequences on employment dynamics - macroeconomic and structural conditions matter as well. Supply side innovations - as the decision to digitalize production processes as a way to increase efficiency -, for example, are more likely to materialize when demand and growth prospects are enough attractive to induce firms to digitalize labour and organizational models. In this respect, digitalization is likely to unfold unevenly across sectors given the diversified demand and growth dynamics that might characterize each industry.

In order to capture the relationship between digitalization and employment accounting for this complex set of supply and demand factors, we resort on regression analysis. The latter builds upon three different specifications each referring to a distinct digital dimension: using digital tools; performing digital task; being equipped with digital skills (see the thorough description of the three indicators provided in the previous section). Employment changes (over the period 2011-16) are studied in relation to the relative 'digitalization' of occupation-industry pairs as well as to the intertwining of digitalization, on one side, and the degree of task-routinarity, on the other. That is, we explore occupation-sector employment trajectories explicitly considering the relative digital intensity of each 'cell' together with the by-occupation degree of task-routinarity as measured by the RTI index (Autor et al. 2003). The econometric specifications include also a number of additional regressors aimed at controlling for some of the occupation sector-specific factors enumerated above, factors which might contribute shaping the digitalization-employment nexus.

The three specifications adopted for the analysis are formalized as follows: 


$$
\begin{gathered}
\Delta N_{i j}=\alpha+\beta \text { DigitalUse }_{i}+\delta \text { RTIindex }_{i}+\theta X_{i j}+\varphi Y_{i}+Z_{j}+\varepsilon_{i j} \\
\Delta N_{i j}=\alpha+\beta \text { Digital Tasks }_{i}+\delta \text { RTIindex }_{i}+\theta X_{i j}+\varphi Y_{i}+Z_{j}+\varepsilon_{i j} \\
\Delta N_{i j}=\alpha+\beta \text { Digital Skills }_{i}+\delta \text { RTIindex }_{i}+\theta X_{i j}+\varphi Y_{i}+Z_{j}+\varepsilon_{i j}
\end{gathered}
$$

where the $i j$ pair correspond, respectively, to the $4^{\text {th }}$ digitISCO 08 occupational and to the $1^{\text {st }}$ digit NACE Rev.2 (Ateco 2007) sectoral identifiers. Concerning variables, $\Delta N$ stands for the long term employment change (2011-2016) by occupation-sector computed as log difference; Digital Use is theindicator ranging between 0 and 100 and capturing the relative importance of digital tools to perform the operations required by each 4-digit occupation included in the analysis; Digital Tasks ranges between 0 and 100 and refers to the relative importance of 'digital tasks' for each occupation $i$; Digital Skills (share over total activities characterizing a certain occupation i) is the indicator reporting the relative intensity of 'digital skills' characterizing each occupation. ${ }^{10}$ In order to account for the degree of routiness at the occupation level we rely on the RTI index provided by the ICP for each 4-digit occupation. The $X_{i j}$ matrix includes a set of occupation-sector controls drawn from the Italian Labour Force Survey (LFS), and namely: the share of young employees (15-34 years old); the share of women; the share of employees with temporary contracts; the share of employees having a part-time contract over the total. Such controls are relevant since they allow accounting for important heterogeneities that might affect the employmentdigitization relationship. To explicitly account for the role of technological change and innovation we introduce an additional indicator $\left(Y_{i}\right)$ stemming from the ICP and capturing process innovation intensity at the 4-digit occupation level (i.e. share of respondents belonging to a certain occupation declaring that a process innovation has been introduced in their workplace during the last three years). Finally, sectoral fixed effects $Z_{j}$ are included in all the estimations allowing to control, at least partly, for structural heterogeneities as well as for sectoral differences in the dynamics of demand. A key element of novelty characterizing specifications (1)-(3) regards the availability of detailed and precise digitalization indicators (use, tasks and skills) at a high level of disaggregation. On the other hand, the ICP provides us with the most precise available occupation-level measure of routine-task - i.e. the RTI - making it possible to qualify the employment-digitalization relationship according to the relative degree of routineness of tasks performed by each occupation $i$. In all estimations, the dependent variable refers to changes in employment between 2011 and 2016, while all regressors are computed at the initial year (2011).

As a first step, we estimate specification (1)-(3) testing the simple $\Delta N$-Digitization relation distinguishing by digital dimension and including all the occupation and sector-level controls discussed above. Subsequently, we add the RTI indicator among the regressors to test whether the latter is capable to affect the occupation-sector employment dynamics. In order to explicitly account for the linkage between digitalization and degree of task- routineness, we expand specifications (1)-(3) introducing the interaction between digital (use, tasks or skills) intensity and degree of routineness (routine-task) as captured by the RTI.

$$
\begin{gathered}
\Delta N_{i j}=\alpha+\beta \text { DigitalUse }_{i}+\delta R T I_{i}+\gamma \text { Digital Use }_{i} * R T I_{i}+\theta X_{i j}+\varphi Y_{i}+Z_{j}+\varepsilon_{i j} \\
\Delta N_{i j}=\alpha+\beta \text { Digital Task }_{i}+\delta R T I_{i}+\gamma \text { Digital Tasks }_{i} * R T I_{i}+\theta X_{i j}+\varphi Y_{i}+Z_{j}+\varepsilon_{i j} \\
\Delta N_{i j}=\alpha+\beta \text { Digital Skills }_{i}+\delta R T I_{i}+\gamma \text { Digital Skills }_{i} * R T I_{i}+\theta X_{i j}+\varphi Y_{i}+Z_{j}+\varepsilon_{i j}
\end{gathered}
$$

\footnotetext{
${ }^{10}$ Note that all digital indicators are sector invariant.
} 
In specifications (4)-(6), the coefficient of major interest is $\gamma$ - the one associated with the interaction term - since it reports the potentially additional positive (negative) employment effect of digitalization observable given the occupation-specific degree of task routineness. Excluding the introduction of the interaction term, however, specifications (4)-(6) perfectly overlap with (1)-(3). Regressions are estimated relying on the Weighted Ordinary Least Squares (WLS) estimator. Standard errors are adjusted in order to control for heteroscedasticity and accounting for number of employees at the initial period for each occupation-sector cell. ${ }^{11}$

\section{Results}

The results, for all the above-mentioned specifications, are reported in table 5. As a first remark, it is worth noticing that the three different digitalization dimensions included in the analysis are heterogeneously associated with the change in employment. Occupation-sectors where the usage of digital tools is relatively more intense (i.e. Digital Use indicator) do not show any statistically significant difference, vis-à-vis the sample average, with respect to the dynamics of employment. The same holds for the intensity of digital tasks (i.e. Digital Tasks indicator), while a positive and statistically significant association is found in the case of occupation-sectors with workers characterized by higher digital skills endowments (i.e. Digital Skills indicator). All things being equal, thus, digitization does not seem to affect employment negatively as some influential contributions would have suggested (i.e. see, among the others, Frey and Osborne, 2017) while, if anything, a positive association is - in line with the findings of Van Roy et al. (2018). The picture does not change when the degree of task routineness is accounted for by including the RTI index among the regressors (columns 2, 5 and 8). Remarkably, the positive relationship between the change in employment and the intensity of digital skills remains significant despite the inclusion of the RTI index pointing to a quite robust association. Some differences emerge when digitization and routineness are jointly considered using interaction terms. Now, the occupationsector cells characterized, at the same time, by a relatively intense use of digital tools or by a relatively high importance of digital tasks as well as by a strong degree of routineness (i.e. high levels of the RTI index) seem to be penalized in terms of employment dynamics. In fact, in both the specifications including the Digital Use and Task indicators (columns 3 and 6) the interaction with the RTI turns out to be negative and (slightly) statistically significant. The same is not true in the case of Digital Skills indicator. The negative and statistically significant relation between the change in employment and the Digital-RTI interaction term reported in table 5 might be interpreted as a partial confirmation of the hypothesis made above concerning the combination of technological and task-related elements in affecting employment. While the use of digital tools or the undertaking of digital tasks do not seem to affect the employment dynamics at the occupation-sector level, the same elements became potentially 'labor disruptive' if occupations are prevalently characterized by routine tasks (i.e. encodable and easily replicable by machine, digital and smart tools). Looking at controls, most of the variability seems to be captured by the sectoral dummies included in the models (i.e. a large part of the occupation-sector controls turns out to be not significant). The only exception is represented by the share of temporary employees which displays a positive and significant (but not strong) association with employment excluding the specifications in which the Digital Use indicator is included. Indeed, this evidence is in line with much of the empirical literature studying the post-2008 evolution of the Italian labor market, reporting a continuous increase in the share of temporary employment (on this point, see Cirillo et al. 2017; Cirillo and Ricci, 2019).

${ }^{11}$ In the Appendix we show the main descriptive statistics for variables used in the regression analysis (see table A.3). 
Table 5. Results of econometric estimates

\begin{tabular}{|c|c|c|c|c|c|c|c|c|c|}
\hline & \multicolumn{9}{|c|}{ Employment rate of change (2011-2016) } \\
\hline & (1) & (2) & (3) & (4) & (5) & (6) & (7) & (8) & (9) \\
\hline Digital Use & $\begin{array}{l}-0.000187 \\
(-0.22)\end{array}$ & $\begin{array}{l}-0.000371 \\
(-0.40)\end{array}$ & $\begin{array}{l}0.00449 * \\
(2.08)\end{array}$ & & & & & & \\
\hline Digital Tasks & & & & $\begin{array}{l}0.00249 \\
(1.65)\end{array}$ & $\begin{array}{l}0.00255 \\
(1.69)\end{array}$ & $\begin{array}{l}0.0206^{*} \\
(2.23)\end{array}$ & & & \\
\hline Digital Skills & & & & & & & $\begin{array}{l}0.00260^{* *} \\
(2.60)\end{array}$ & $\begin{array}{l}0.00287^{* *} \\
(2.60)\end{array}$ & $\begin{array}{l}0.00713^{*} \\
(2.31)\end{array}$ \\
\hline RTI index & & $\begin{array}{l}-0.000662 \\
(-0.52)\end{array}$ & $\begin{array}{l}0.00450 \\
(1.91)\end{array}$ & & $\begin{array}{l}-0.000564 \\
(-0.49)\end{array}$ & $\begin{array}{l}-0.00000603 \\
(-0.01)\end{array}$ & & $\begin{array}{l}0.000654 \\
(0.53)\end{array}$ & $\begin{array}{l}0.00314 \\
(1.53)\end{array}$ \\
\hline RTI*Digital use & & & $\begin{array}{l}-0.000103^{*} \\
(-2.50)\end{array}$ & & & & & & \\
\hline RTI*Digital Task & & & & & & $\begin{array}{l}-0.000398^{*} \\
(-1.95)\end{array}$ & & & \\
\hline RTI*Digital Skills & & & & & & & & & $\begin{array}{l}-0.000105 \\
(-1.38)\end{array}$ \\
\hline Process innovations & $\begin{array}{l}-0.384^{* *} \\
(-2.84)\end{array}$ & $\begin{array}{l}-0.380^{* *} \\
(-2.78)\end{array}$ & $\begin{array}{l}-0.385^{* *} \\
(-2.87)\end{array}$ & $\begin{array}{l}-0.435^{* * *} \\
(-3.57)\end{array}$ & $\begin{array}{l}-0.444^{* * *} \\
(-3.67)\end{array}$ & $\begin{array}{l}-0.446 \text { *** } \\
(-3.68)\end{array}$ & $\begin{array}{l}-0.487^{* * *} \\
(-3.90)\end{array}$ & $\begin{array}{l}-0.487^{* * *} \\
(-3.90)\end{array}$ & $\begin{array}{l}-0.473^{* * *} \\
(-3.81)\end{array}$ \\
\hline Share of young workers & $\begin{array}{l}0.148 \\
(1.03)\end{array}$ & $\begin{array}{l}0.152 \\
(1.07)\end{array}$ & $\begin{array}{l}0.173 \\
(1.25)\end{array}$ & $\begin{array}{l}0.121 \\
(0.84)\end{array}$ & $\begin{array}{l}0.122 \\
(0.84)\end{array}$ & $\begin{array}{l}0.119 \\
(0.83)\end{array}$ & $\begin{array}{l}0.123 \\
(0.85)\end{array}$ & $\begin{array}{l}0.119 \\
(0.83)\end{array}$ & $\begin{array}{l}0.132 \\
(0.92)\end{array}$ \\
\hline Share of female workers & $\begin{array}{l}0.0417 \\
(0.61)\end{array}$ & $\begin{array}{l}0.0430 \\
(0.62)\end{array}$ & $\begin{array}{l}0.0651 \\
(0.96)\end{array}$ & $\begin{array}{l}0.0465 \\
(0.67)\end{array}$ & $\begin{array}{l}0.0463 \\
(0.66)\end{array}$ & $\begin{array}{l}0.0452 \\
(0.65)\end{array}$ & $\begin{array}{l}0.0726 \\
(1.02)\end{array}$ & $\begin{array}{l}0.0763 \\
(1.07)\end{array}$ & $\begin{array}{l}0.0797 \\
(1.12)\end{array}$ \\
\hline Share of temporary employees & $\begin{array}{l}0.240 \\
(1.86)\end{array}$ & $\begin{array}{l}0.243 \\
(1.89)\end{array}$ & $\begin{array}{l}0.220 \\
(1.70)\end{array}$ & $\begin{array}{l}0.261 * \\
(2.03)\end{array}$ & $\begin{array}{l}0.272^{*} \\
(2.12)\end{array}$ & $\begin{array}{l}0.261^{*} \\
(2.04)\end{array}$ & $\begin{array}{l}0.291 * \\
(2.27)\end{array}$ & $\begin{array}{l}0.283^{*} \\
(2.21)\end{array}$ & $\begin{array}{l}0.257^{*} \\
(2.05)\end{array}$ \\
\hline Share of part-time workers & $\begin{array}{l}0.226 \\
(1.32)\end{array}$ & $\begin{array}{l}0.216 \\
(1.23)\end{array}$ & $\begin{array}{l}0.268 \\
(1.55)\end{array}$ & $\begin{array}{l}0.219 \\
(1.25)\end{array}$ & $\begin{array}{l}0.206 \\
(1.16)\end{array}$ & $\begin{array}{l}0.218 \\
(1.23)\end{array}$ & $\begin{array}{l}0.179 \\
(1.01)\end{array}$ & $\begin{array}{l}0.189 \\
(1.07)\end{array}$ & $\begin{array}{l}0.218 \\
(1.23)\end{array}$ \\
\hline Sector dummies & Yes & Yes & Yes & Yes & Yes & Yes & Yes & Yes & Yes \\
\hline Constant & $\begin{array}{l}-0.236 \\
(-1.11)\end{array}$ & $\begin{array}{l}-0.188 \\
(-0.78)\end{array}$ & $\begin{array}{l}-0.505 \\
(-1.87)\end{array}$ & $\begin{array}{l}-0.303 \\
(-1.53)\end{array}$ & $\begin{array}{l}-0.268 \\
(-1.26)\end{array}$ & $\begin{array}{l}-0.303 \\
(-1.43)\end{array}$ & $\begin{array}{l}-0.313 \\
(-1.54)\end{array}$ & $\begin{array}{l}-0.364 \\
(-1.67)\end{array}$ & $\begin{array}{l}-0.491^{*} \\
(-2.07)\end{array}$ \\
\hline $\mathrm{N}$ & 2281 & 2281 & 2281 & 2281 & 2281 & 2281 & 2281 & 2281 & 2281 \\
\hline $\begin{array}{l}\mathrm{t} \text { statistics in parentheses } \\
* \mathrm{p}<0.05, * * \mathrm{p}<0.01, * * * \mathrm{p}<0.0\end{array}$ & & & & & & & & & \\
\hline
\end{tabular}




\section{Conclusions}

The debate on the impact of digitalization on employment has been dominated more by impressionistic views: on the one hand, some authors have depicted a scenario of mass technological unemployment; on the other hand, others have envisaged labour opportunities resulting from digitalization. Indeed, the empirical evidence on the impact of digitalization on employment is still limited mainly because of challenges in conceptualising effective measurements of a complex phenomenon such as digitalization and in operationalizing digitalization through adequate indicators. Until now, digitalization has been associated to routineness of jobs building on the conceptual framework proposed by Autor and Dorn (2013) according to which highly routinized professions are those more exposed to job substitution. In the neoclassical framework, technology is treated as a shock affecting labour demand and subsequently employment according to the elasticity of substitution between labour and capital. According to this viewpoint, tasks are units of work activity producing output; skills are human capabilities to perform tasks. The effect of technical change on labour demand depends in turn on the type of task content involved in each profession: in particular, routine tasks which are easier to codify and automate are more likely to be replaced by machines. In this view, digitalization is considered as a synonymous of routineness because routine tasks tend to be more digitalized than non-routine labour activities.

In this work, we have tried to overcome such simplistic perspective, analyzing and measuring digitalization and routineness of tasks as distinct phenomena, exploring their relevance across industries and types of professions and assessing econometrically their independent and combined effects on employment. This has been possible thanks to the exploitation of the data provided by INAPP-ISTAT Survey on Occupations. An important value added of this contribution has consisted in the use of a robust set of indicators on digitalization and routineness able to capture the heterogeneous nature of such phenomena. To our knowledge, few studies have explored digitalization as a complex process entailing different dimensions of work activities - such as digital tools, skills and tasks - and, mostly, the interrelations between digital and routine attributes of work.

The empirical results presented in this paper can be summarized as follows. Digitalization and routineness have emerged as composite and multifaceted phenomena showing marked sectoral specificities and being strongly associated with the skill content of labour professions. In particular, all digital indicators have been found to be positively related to the level of skills while the level of routineness has emerged to be negatively associated to the skill content of labour activities. Routineness and digitalization do not appear as synonymous and do not seem to proceed in parallel. On the contrary, they seem to be linked by an inverse relationship and this can be explained by the fact that the level of digitalization is high among high-skilled professions which are characterized in turn by low level of routinization.

The descriptive evidence presented in section 4 has shown that the relationships linking digitalization and routineness with the dynamics of employment are complex and differ across manufacturing and services industries. Professions characterized by higher digital skills grow faster compared to the others (although this holds only in manufacturing sector) while a negative employment dynamics is found among profession characterized by high level of digitalization and routineness. Both results are confirmed by the econometric analysis presented in section 5. More specifically, the econometric estimates confirm that professions characterized by an intense use of digital tools - or by a relatively high importance of digital tasks - and, jointly, by a strong degree of routineness tend to be penalized in employment terms. 


\section{References}

Acemoglu, D., Restrepo, P. 2017. Robots and jobs: evidence from us labour markets. Nber working paper series, n. 23285 (http://www.nber.org/papers/w23285)

Acemoglu, D., \& Restrepo, P. 2018. The Race between Man and Machine: Implications of Technology for Growth, Factor Shares, and Employment. American Economic Review. 108(6), 1488-1542.

Akerman, A., Gaarder, I., Mogstad, M. 2015. The Skill Complementarity of Broadband Internet. The Quarterly Journal of Economics. 130(4), 1781-1824.

Arntz, M., Gregory, T., Zierahn, U. 2016. The risk of automation for jobs in OECD countries: A comparative analysis. OECD Social, Employment, and Migration Working Papers, n. 189.

Aubert, P., Caroli, E., Roger, M. 2006. New technologies, organization and age: firm level evidence. The Economic Journal. 116, 73-93.

Autor, D., Levy, F., Murnane, R.J. 2003. The skill content of recent technological change: an empirical exploration. The Quarterly Journal of Economics. 118(4), 1279-1333.

Autor, D. H., Katz, L.F., Kearney, M. S. 2006. The Polarization of the U.S. Labor Market. American Economic Review Papers and Proceedings. 96, 189-194.

Autor, D. 2013. The “task approach” to labor markets: an overview. Journal for Labour Market Research. 46(3), pp. 185-199.

Autor, D., Dorn, D. 2009. The Skill Content of Jobs and the Evolution of the Wage Structure-This Job is" Getting Old": Measuring Changes in Job Opportunities using Occupational Age Structure. American Economic Review. 99(2), 45.

Autor, D., Dorn, D. 2013. The growth of low-skill service jobs and the polarization of the US labor market. American Economic Review. 103(5), 1553-97.

Böckerman, P., Laaksonen, S., Vainiomäki, J. 2019. Does ICT Usage Erode Routine Occupations at the Firm Level?, Labour 33 (1) 26-47.

Böckerman, P., Laaksonen, S., Vainiomäki, J. 2016. Are Jobs More Polarized in ICT Firms?. IZA working paper. No. 9851.

Bogliacino, F., Lucchese, M. 2015. Endogenous skill-biased technical change: testing for demand-pull effect. Industrial and Corporate Change, 25(2), 227-243.

Brynjolfsson, E., McAfee, A. 2011. The second Machine age, W. W. Norton \& Company, New York.

Calvino, F., Criscuolo, C., Marcolin, L., Squicciarini, M. 2018. A taxonomy of digital intensive sectors, OECD Science. Technology and Industry Working Papers. 2018/14.

Cirillo, V. 2016. Employment polarisation in European industries. International Labour Review. 157(1), 39-63.

Cirillo, V., Fana, M., Guarascio, D. 2017. Labour market reforms in Italy: Evaluating the effects of the Jobs Act. Economia Politica, 34(2), 211-232. 
Cirillo, V., Pianta, M., Nascia, L. 2018. Technology and occupations in business cycles. Sustainability, 10(2), 463.

Cirillo, V., Rinaldini, M., Staccioli, J., Virgillito, M. E. 2018. Workers' awareness context in Italian 4.0 factories (No. 240). GLO Discussion Paper.

Cirillo V., Ricci A. 2019. Produttività salari e profitti: il ruolo dei contratti a tempo determinato, Inapp Paper n. 16, Roma, INAPP.

Codagnone, C. 2009. Vienna Study on Inclusive Innovation for Growth and Cohesion: Modelling and demonstrating the impact of eInclusion. DG Information Society and Media, ICT for Inclusion Unit.

Cortes G. M., Salvatori A. (2015) 'Task Specialization Within Establishments and the Decline of Routine Employment', Unpublished manuscript, University of Manchester and RCEA.

Dauth, W., Findeisen, S., Südekum, J., Wößner, N. 2017. German robots - the Impact of Industrial Robots on Workers. IAB-Discussion Paper, 30/2017.

Eurofound. 2016. What do Europeans do at work? A task-based analysis. European Jobs Monitor. Publications Office of the European Union, Luxembourg.

Evangelista, R., Guerrieri, P., Meliciani, V. 2014. The economic impact of digital technologies in Europe. Economics of Innovation and new technology. 23(8), 802-824.

Fernández-Macías, E., Hurley, J. 2016. Routine-biased technical change and job polarization in Europe. Socio-Economic Review. 15(3), 563-585.

Freeman, C., Louçã, F. 2001. As Time Goes By: From the Industrial Revolutions to the Information Revolution. Oxford University Press, Oxford.

Frey, C. B., Osborne, M. A. 2017. The Future of Employment: How Susceptible are Jobs to Computerisation? Technological Forecasting and Social Change. 114, 254-280.

Friedberg, L. 2003. The impact of technological change on older workers: evidence from data on computer Use. Industrial and Labor Relations Review. 56 (3), 511-529.

Gaggl, P., Wright, G. C. 2017. A Short Run View of What Computers Do: Evidence from a UK. Economics Discussion Papers. 10012. University of Essex, Department of Economics.

Goos, M., Manning, A. 2007. Lousy and lovely jobs: The rising polarization of work in Britain. Review of Economics and Statistics. 89, 118-133.

Goos, M., Manning, A., Salomons, A. 2014. Explaining Job Polarization: Routine-Biased Technological Change and Offshoring. American Economic Review. 104(8), 2509-2526.

Graetz, G., Michaels, G. 2015. Robots at Work. CEP Discussion Paper 1335, Revised Version June 22, 2017.

Gualtieri, V., Guarascio, D., Quaranta, R. 2018. Routine tasks and the dynamics of Italian employment. INAPP Policy brief, $7 / 2018$.

Guerrieri, P., Bentivegna, S. (eds) 2012. The economic impact of digital technologies, Edward Elgar, Cheltenham, UK. 
Kemeny, T., Rigby, D. 2012. Trading away which kind of jobs? Review of World Economics/Weltwirtschaftliches Archiv. 148(1), 1-16.

Krueger, A.B. 1993. How computers have changed the wage structure: evidence from microdata, 19841989. Quarterly Journal of Economics 10(1), 1215-1244.

Machin S. and Van Reenen, J (1998), 'Technology and changes in skill structure: Evidence from seven OECD countries', The Quarterly Journal of Economics, 113(4):1215-1244.

Marcolin, L., S. Miroudot, Squicciarini, M. 2016. Routine jobs, employment and technological innovation in global value chains. OECD Science, Technology and Industry Working Papers. 2016/01. OECD Publishing, Paris.

McKinsey Global Institute. 2015. Digital america: a tale of the haves and have-mores.

Michaels, G., Natraj, A., Van Reenen, J. 2014. Has ICT Polarized Skill Demand? Evidence from Eleven Countries over Twenty-Five Years. The Review of Economics and Statistics. 96(1), 60-77.

OECD. 2004. The Economic Impact of ICT: Measurement, Evidence and Implications. OECD, Paris.

OECD. 2015. OECD Employment Outlook 2015. OECD. Paris.

OECD. 2017. OECD Employment Outlook 2017. OECD. Paris.

OECD. 2018. Job Creation and Local Economic Development 2018: Preparing for the Future of Work. OECD, Paris.

Oesch, D., Rodriguez, Jorge. 2011. Upgrading or polarisation? Occupational change in Britain, Germany, Spain and Switzerland, 1990-2008. Socio-Economic Review. 9(3), 503-531.

Pekkala, Kerr, S., Maczuskij, T., Maliranta M. 2016. Within and Between Firm Trends in Job Polarization: Role of Globalization and Technology. Working Paper No. 41, The Research Institute of the Finnish Economy (ETLA).

van Reenen, J., M., Draca, M., Sadun, R. 2007. Productivity and ICTs: a review of the evidence, in R. Mansell, C. Avgerou, D. Quah, R. Silverstone (eds.), 100-147. The Oxford handbook of information and communication technologies. Oxford University Press, Oxford- Routine Employment', Unpublished manuscript, University of Manchester and RCEA.

Schleife, K. 2006. Computer use and employment status of older workers. An analysis based on individual data. Labour. 20(2), 325-348.

Sebastian, R., Biagi, F. 2018. The Routine Biased Technical Change hypothesis: a critical review. European Commission, Luxembourg. ISBN 978-92-79-94050-7, doi:10.2760/986914, JRC113174.

Spitz-Oner, A. 2006. Technical change, job tasks and rising educational demands: looking outside the wage structure. Journal of Labour Economics. 24(2) 235-270.

Vivarelli, M. 2014. Innovation, employment and skills in advanced and developing countries: A survey of economic literature. Journal of Economic Issues. 48(1), 123-154. 


\section{Appendix}

Figure A1. Digital Use by sector (weighted for number of employees in 2011)

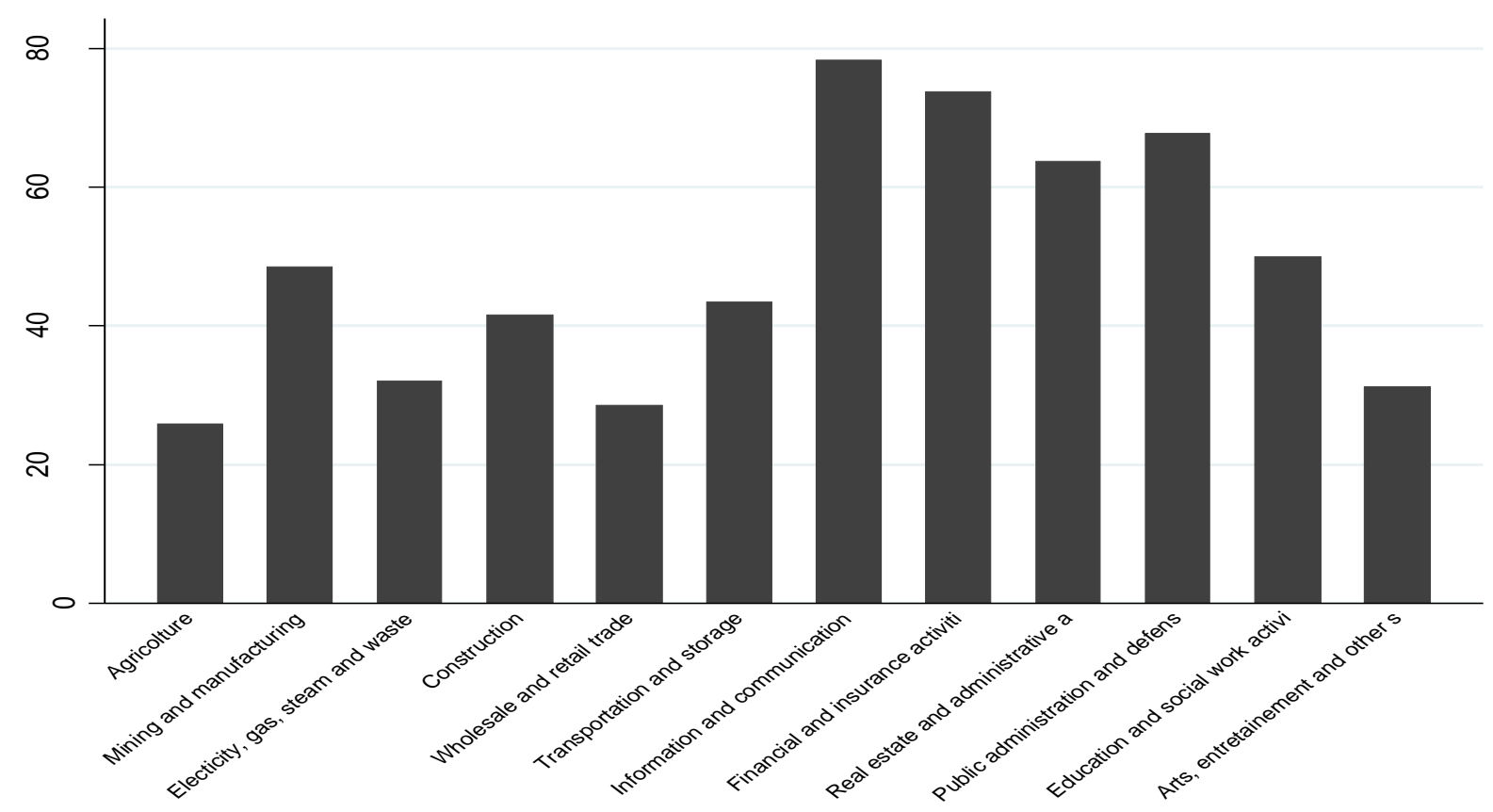

Figure A2. Digital Tasks by sector (weighted for number of employees in 2011)

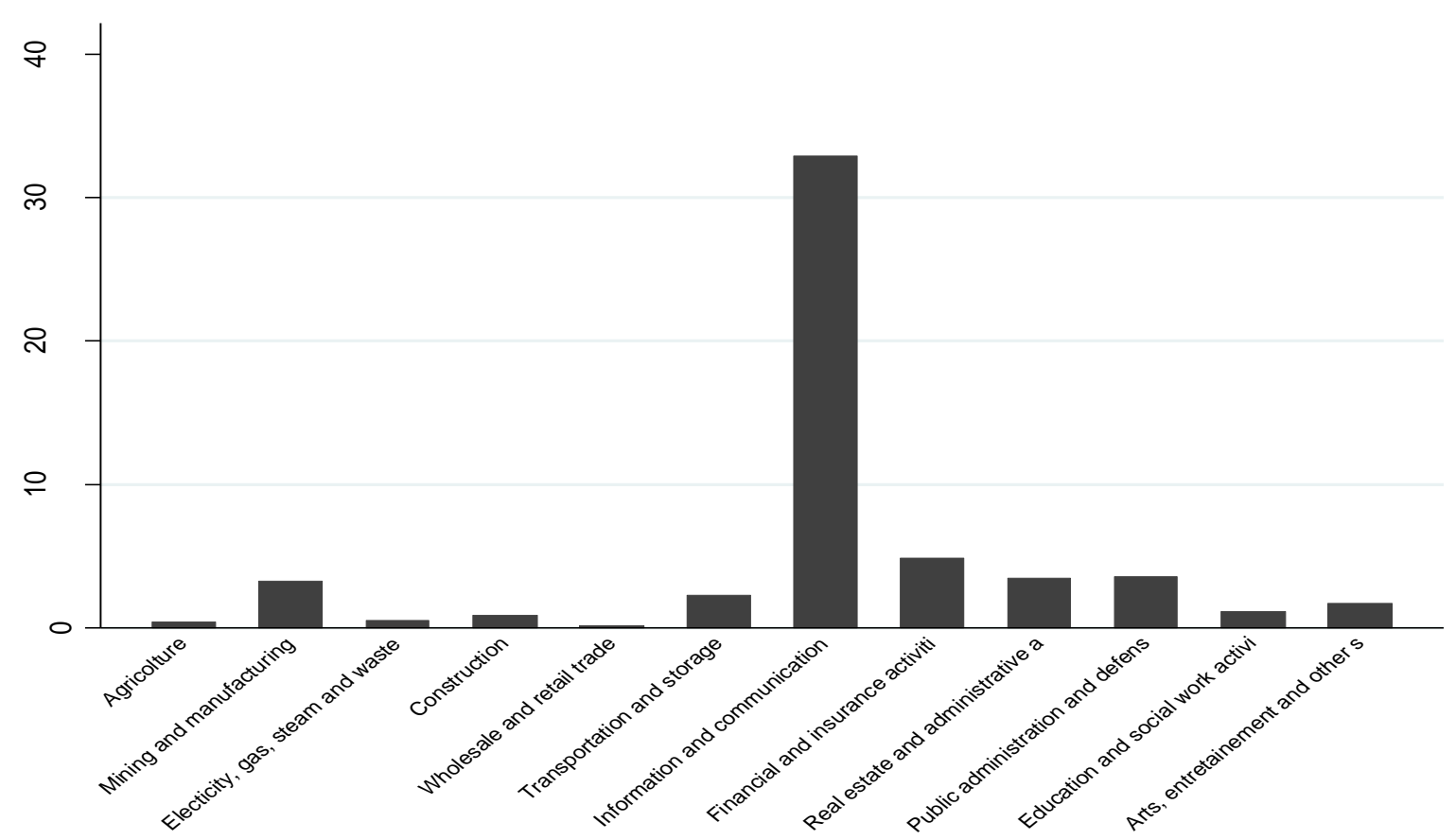


Figure A3. Digital Skills by sector (weighted for number of employees in 2011)

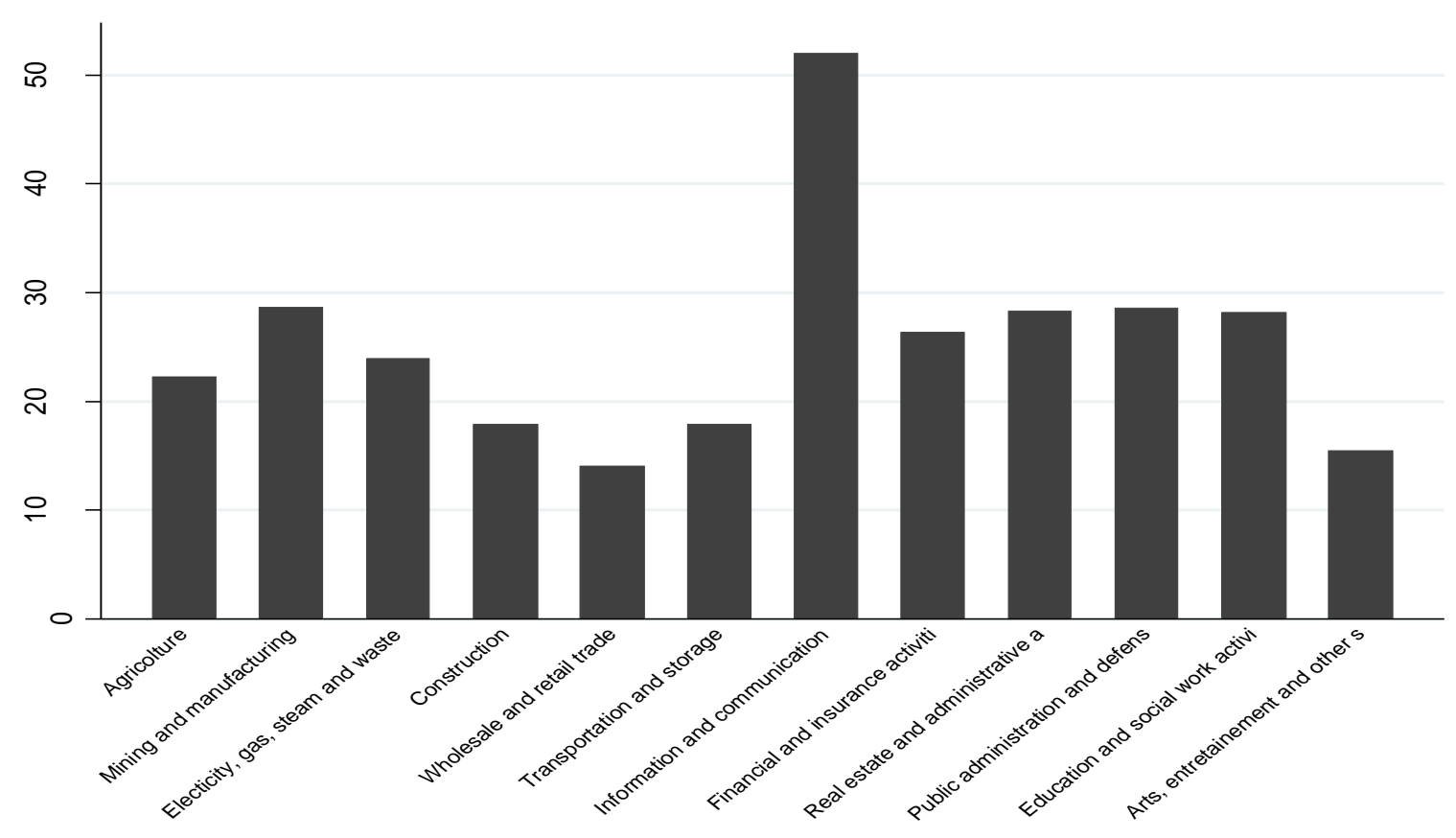

Table A1. Digital and routine indices by professional groups at 1 digit level ISCO.

\begin{tabular}{|c|c|c|c|c|c|c|}
\hline \multirow{3}{*}{$\begin{array}{l} \\
\text { HIGH- } \\
\text { SKILLED }\end{array}$} & \multirow{3}{*}{$\begin{array}{l}\text { DIGITAL USE } \\
\text { Legislators, entrepreneurs } \\
\text { and senior management }\end{array}$} & \multirow{3}{*}{$\begin{array}{l}\text { DIGITA } \\
\text { L TASKS } \\
69.23\end{array}$} & \multirow{3}{*}{$\begin{array}{l}\text { RTI } \\
0.39\end{array}$} & \multirow{3}{*}{$\begin{array}{l}\text { ROUTI } \\
\text { NE } \\
\text { MANUA } \\
\text { L } \\
25.26\end{array}$} & \multirow{2}{*}{\multicolumn{2}{|c|}{$\begin{array}{l}\text { ROUTINE } \\
\text { COGNITIVE }\end{array}$}} \\
\hline & & & & & & \\
\hline & & & & & 37.20 & 26.65 \\
\hline & $\begin{array}{l}\text { Intellectual, scientific and } \\
\text { highly } \\
\text { professions }\end{array}$ & 76.85 & 9.31 & 30.02 & 39.66 & 33.31 \\
\hline & Technical professions & 72.45 & 8.14 & 37.79 & 44.13 & 43.46 \\
\hline \multirow[t]{3}{*}{$\begin{array}{l}\text { MEDIUM- } \\
\text { SKILLED }\end{array}$} & $\begin{array}{l}\text { Executive professions in } \\
\text { office work }\end{array}$ & 71.78 & 5.72 & 52.25 & 46.9 & 59.61 \\
\hline & $\begin{array}{l}\text { Qualified professions in } \\
\text { commercial activities and } \\
\text { services }\end{array}$ & 41.76 & 0.76 & 42.48 & 38.73 & 60.35 \\
\hline & $\begin{array}{l}\text { Craftsmen, specialized } \\
\text { workers and farmers }\end{array}$ & 38.66 & 1.66 & 46.14 & 52.63 & 62.95 \\
\hline \multirow[t]{2}{*}{$\begin{array}{l}\text { LOW- } \\
\text { SKILLED }\end{array}$} & $\begin{array}{l}\text { Plant and Machine operators } \\
\text { and assemblers }\end{array}$ & 30.06 & 1.13 & 56.01 & 58.63 & 75.04 \\
\hline & Elementary occupations & 20.13 & 0.28 & 52.58 & 45.32 & 76.55 \\
\hline
\end{tabular}

Table A2. Rate of employment change by routineness and digitalization of professions (Digital Tasks)

\begin{tabular}{l|ll|l} 
& & & \\
& DIGITAL TASKS $<0.50$ & DIGITAL TASKS $>0.50$ & \\
\hline RTI $<0.25$ & $0.67 \%$ & $-7.30 \%$ & $-0.81 \%$ \\
$0.25>$ RTI $<0.75$ & $5.71 \%$ & $3.74 \%$ & $5.32 \%$ \\
RTI $>0.75$ & $0.87 \%$ & $-12.05 \%$ & $-0.90 \%$ \\
\hline & $2.43 \%$ & $-4.67 \%$ & $1.24 \%$
\end{tabular}


Table A3. Descriptive statistic

\begin{tabular}{|c|c|c|c|c|c|c|c|c|c|c|c|c|c|c|c|c|}
\hline & \multicolumn{4}{|c|}{ All professions } & \multicolumn{4}{|c|}{ High-Skilled } & \multicolumn{4}{|c|}{ Medium-Skilled } & \multicolumn{4}{|c|}{ Low-Skilled } \\
\hline & Mean & $\mathrm{Sd}$ & Min & Max & Mean & $\mathrm{Sd}$ & Min & Max & Mean & $\mathrm{Sd}$ & Min & Max & Mean & $\mathrm{Sd}$ & Min & Max \\
\hline Employment rate of change & -0.14 & 1.02 & -5.24 & 3.90 & -0.04 & 0.99 & -5.01 & 3.90 & -0.28 & 1.04 & -5.24 & 3.74 & -0.11 & 1.05 & -4.90 & 3.62 \\
\hline Digital Use & 56.13 & 24.36 & 0.00 & 100.00 & 73.42 & 11.22 & 7.42 & 100.00 & 49.68 & 22.17 & 0.51 & 88.96 & 25.64 & 15.27 & 0.00 & 71.21 \\
\hline Digital Tasks & 4.46 & 14.30 & 0.00 & 100 & 7.45 & 19.86 & 0.00 & 100.00 & 2.62 & 6.73 & 0.00 & 46.62 & 0.76 & 4.36 & 0.00 & 33.75 \\
\hline Digital Skills & 30.55 & 17.20 & 2.89 & 100 & 41.58 & 17.02 & 4.15 & 100 & 23.79 & 10.91 & 3.53 & 66.16 & 16.89 & 9.99 & 2.89 & 69.27 \\
\hline RTI index & 42.25 & 15.51 & 1.44 & 100 & 33.56 & 12.42 & 1.44 & 65.16 & 46.97 & 13.98 & 13.21 & 83.62 & 54.49 & 13.04 & 24.95 & 100 \\
\hline Process Innovations & 0.24 & 0.14 & 0.00 & 0.80 & 0.27 & 0.14 & 0.00 & 0.80 & 0.24 & 0.15 & 0.00 & 0.71 & 0.17 & 0.11 & 0.00 & 0.57 \\
\hline Share of young employees & 0.26 & 0.26 & 0 & 1 & 0.23 & 0.27 & 0 & 1 & 0.29 & 0.26 & 0 & 1 & 0.25 & 0.25 & 0 & 1 \\
\hline Share of female workers & 0.36 & 0.35 & 0 & 1 & 0.36 & 0.33 & 0 & 1 & 0.40 & 0.36 & 0 & 1 & 0.27 & 0.33 & 0 & 1 \\
\hline Agriculture & 0.05 & 0.21 & 0 & 1 & 0.03 & 0.16 & 0 & 1 & 0.06 & 0.23 & 0 & 1 & 0.07 & 0.26 & 0 & 1 \\
\hline Mining and manufacturing & 0.15 & 0.36 & 0 & 1 & 0.12 & 0.32 & 0 & 1 & 0.16 & 0.36 & 0 & 1 & 0.23 & 0.42 & 0 & 1 \\
\hline Electricity, gas, steam and waste management & 0.06 & 0.24 & 0 & 1 & 0.05 & 0.22 & 0 & 1 & 0.07 & 0.26 & 0 & 1 & 0.07 & 0.25 & 0 & 1 \\
\hline Construction & 0.10 & 0.30 & 0 & 1 & 0.08 & 0.27 & 0 & 1 & 0.12 & 0.32 & 0 & 1 & 0.12 & 0.32 & 0 & 1 \\
\hline Wholesale and retail trade & 0.05 & 0.21 & 0 & 1 & 0.03 & 0.18 & 0 & 1 & 0.06 & 0.24 & 0 & 1 & 0.06 & 0.23 & 0 & 1 \\
\hline Transportation and storage & 0.08 & 0.27 & 0 & 1 & 0.07 & 0.26 & 0 & 1 & 0.08 & 0.27 & 0 & 1 & 0.09 & 0.28 & 0 & 1 \\
\hline Information and communication & 0.05 & 0.22 & 0 & 1 & 0.07 & 0.25 & 0 & 1 & 0.04 & 0.21 & 0 & 1 & 0.02 & 0.15 & 0 & 1 \\
\hline Financial and insurance activities & 0.03 & 0.18 & 0 & 1 & 0.05 & 0.21 & 0 & 1 & 0.03 & 0.17 & 0 & 1 & 0.01 & 0.11 & 0 & 1 \\
\hline Real estate and administrative activities & 0.13 & 0.34 & 0 & 1 & 0.14 & 0.35 & 0 & 1 & 0.12 & 0.32 & 0 & 1 & 0.13 & 0.34 & 0 & 1 \\
\hline Public administration and defence & 0.09 & 0.29 & 0 & 1 & 0.12 & 0.32 & 0 & 1 & 0.07 & 0.25 & 0 & 1 & 0.07 & 0.25 & 0 & 1 \\
\hline Education and social work activities & 0.10 & 0.30 & 0 & 1 & 0.13 & 0.34 & 0 & 1 & 0.08 & 0.28 & 0 & 1 & 0.06 & 0.23 & 0 & 1 \\
\hline Arts, entertainment and other services & 0.11 & 0.31 & 0 & 1 & 0.11 & 0.32 & 0 & 1 & 0.12 & 0.32 & 0 & 1 & 0.08 & 0.27 & 0 & 1 \\
\hline Number of observations & 2293 & & & & 1028 & & & & 870 & & & & 395 & & & \\
\hline
\end{tabular}


Table A4: Digital tasks

Digital activities

1. Record content (music, video, etc) in digital archives

2. Update archives or databases

3. Update databases

4. Update personnel databases

5. Update software on machinery operation

6. Update or query databases

7. Update or input data and measurements in the computers controlling machinery (check measurements, etc.)

8. Analyse software malfunctions

9. Analyse technical specifications and features of network and telecom equipment

10. Analyse or find client needs (analyse operational problems, define software and hardware requirements, etc.)

11. Analyse or find client needs (feasibility studies, identifying appropriate tools, analyse operational problems, define software and hardware requirements, etc.)

12. Analyse, plan and develop software systems

13. Activating terminals executing plays

14. Equip and program machine tools depending on task

15. Equip and program machinery and robots (turn robots on and off, program tasks, etc.)

16. Equip and program machine tools based on task (milling machine, lathe, sanding machine, etc.)

17. Configure or install IT systems

18. Query databases

19. Contact (also electronically) the customer to receive data to carry out interviews

20. Check the reactor loads by computer

21. Check plays and wins from a terminal

22. Check plays and wins from a terminal, and check sporting results

23. Check operational parameters of robots

24. Check furnace temperature and draw reports on the temperature measured by the computer system

25. Track remotely merchandise shipments

26. Coordinate or carry out lab experiments, computer simulations, observations

27. Coordinate lab activities and prepare exercises (new technologies, network security, etc)

28. Fix or alter digital photos

29. Create and update a supplier database

30. Create, update and manage a database

31. Create, modify or test software and applications

32. Supervise and introduce technological innovations

33. Supervise and introduce technological or product innovation

34. Supervise the digitalisation of services (cataloguing, documentation, bibliographic research, etc.)

35. Supervise the mechanical or digital layout of text, images or other symbols to execute

36. Supervise the preservation and possible recovery of digitized records

37. Supervise the preservation, protection, and possible recovery of digitized records

38. Draw projects on the computer 
39. Translate (business, legal, or technical documents, advertisement copy, web content, etc.)

40. Editing digital images

41. Research material for users (library search, on the web, or in other libraries)

42. Image colouring (by paintbrush or by computer)

43. Run computer simulations

44. Calibrate components with computer or similar technologies

45. Perform software tests

46. Extract data from digital archives

47. Advise clients on software or IT systems

48. Manage databases or archives

49. Manage personnel data

50. Manage and update web advertisement copy

51. Manage and update website contents

52. Manage and supervise the sales network

53. Manage the database structure

54. Manage the digital labs and IT equipment

55. Manage IT networks

56. Manage servers

57. Manage IT systems and networks

58. Set the print layout digitally

59. Set the technical specifications for application development

60. Set the technical specifications for application development (ie, develop programs, procedures, interface, etc.)

61. Find and fix software bugs

62. Identify and develop software solutions and procedures

63. Input data in digital archives

64. Install IT equipment

65. Install automated vending machines

66. Install and update IT networks

67. Install and update network and communication equipment

68. Install or expand telephone networks

69. Install on-board machines or equipment (set up dredges, install electric equipment such as echo-sounders, radar, auto-pilot, etc.)

70. Install programs or applications

71. Install IT networks

72. Install telephone networks

73. Install operating systems and applications

74. Install software

75. Merge data collected with digital databases

76. Submit reports or information electronically

77. Update and optimize IT networks

78. Update and repair network and telecommunication equipment

79. Edit software or other applications

80. Supervise databases

81. Supervise and maintain IT systems and networks 
82. Supervise the performance of IT systems and networks

83. Assemble or disassemble components or parts of personal computers

84. Organise and manage inventories, archives and databases

85. Organise the documentation on artwork on microfilm or other digital media

86. Organise or perform laboratory experiment or computer simulation

87. Customise software

88. Design and supervise IT security systems

89. Design and implement solutions for optimising systems

90. Design and implement solutions for optimising network and telecommunication systems

91. Design and develop websites

92. Design and develop systems or telecommunication network apparatus

93. Develop teaching programs (general or customized)

94. Design IT or telecom systems

95. Design, implement and maintain software or IT systems for industrial processes management

96. Design, develop and test database management systems

97. Design, develop and test software for various use cases

98. Develop websites

99. Record date on origin and destination by digital means

100. Repair components or parts of personal computers

101. Reboot machine and robots in case of disruption and intervene in the production line in case of mechanical malfunction

102. Reproduce documents on digital medium

103. Reproduce or print on different media (digital, paper, etc.) documents or images, negatives and photographs (scanning, etc.)

104. Writing program code

105. Study and apply software solutions to solve problems

106. Develop software and other applications

107. Perform ordinary or extraordinary maintenance on systems or programs

108. Test the optimisation of engines

109. Test hardware components, networks, or computing peripherals

110. Send documents electronically to the relevant department

111. Use database or IT systems

112. Use pc and CAD systems to obtain the shape of the artefact

113. Use industry-specific software

114. Use IT systems to query archives or databases

115. Use custom accounting management software

116. Use navigation tools and equipment (cartographic plotter, sounding lead, radar, GPS, navigation computer, etc.)

117. Use digital tools to make technical drawings

118. Use digital tools to make technical drawings, lay out text and images

119. Use digital tools to make videos

120. Inspect and test network equipment

121. Inspect and test network and telecommunication equipment

122. Inspect and check online services

123. Analyse system access and manage profiles 


\begin{tabular}{|ll|}
\hline 124. & Develop and implement security measures for IT systems \\
125. & Inspect IT system efficiency \\
126. & Inspect protection and efficiency of IT systems \\
127. & Manage electronic delivery systems \\
128. & Oversee and service industrial production management systems \\
129. & Design systems and electronic equipment \\
130. & Design, develop and maintain electronic systems \\
131. & Develop electronic equipment and systems \\
\hline
\end{tabular}

